\title{
La nueva administración pública: el equilibrio entre la gobernanza política y la autonomía administrativa*
}

\section{Tom Christensen y Per Lagreid}

Los sistemas político-administrativos de las democracias occidentales se basan en una mezcla compleja ya menudo ambigua de normas y valores relacionados con el control político-administrativo, códigos de conducta profesional, procesos adecuados y un gobierno basado en reglas, responsabilidad democrática, ética del servicio público y participación de los grupos afectados (Olsen, 1998). Esa complejidad de los modernos sistemas de servicio civil con una pluralidad de funciones ha sido puesta en tela de juicio en los últimos veinte años por el modelo de la nueva administración pública, una ola reformista que representa un modelo económico universal de gobierno y organización que centra su atención en la eficiencia. Sin embargo, poco se ha hecho en lo que respecta a la evaluación de los efectos de las reformas del modelo de la nueva administración pública, ni en lo relacionado con la consecución de la importante meta de la eficiencia ni en cuanto se refiere a los efectos sobre otras metas, como la de la gobernanza política, ${ }^{1}$ lo cual se debe parcialmente al hecho de que no se trata de una tarea fácil (Peters y Savoie, 1998). Existen pocas pruebas de que la aplicación de las estrategias de reforma basadas en el modelo de la nueva administración pública produzca realmente los resultados deseados. A menudo, los efectos y consecuencias del modelo de la nueva administración pública se dan por supuestos o se prometen, pero no se documentan. Dichos efectos son difíciles de cuantificar y muy controvertidos: se argumenta en contra de las relaciones entre las causas y los efectos; los indicadores de la eficiencia y la efectividad son elusivos con mucha frecuencia; los efectos secundarios son difíciles de rastrear; y frecuentemente la metodología que se utiliza en la evaluación

Tom

Christensen es investigador del Departamento de Ciencia Política en la Universidad de Oslo.

Per Lægreid es investigador del Departamento e Administración y Teoría de la Organización en el LOS-Center de la Universidad de Bergen.

Contato: tom.christensen@ stv.uio.no

per.lagreid@ aorg.uib.no

*Artigo publicado na Revista Gestión y Politica Pública, vol. X, no 1 , México, primeiro semestre, 2001. 
del modelo de la nueva administración pública es insuficiente (Hesse, Hood y Peters, 1999; Keauden y Van Mierlo, 1998; Olsen, 1996; Pollitt, 1995).

En este trabajo centraremos nuestra atención en un conjunto de efectos y consecuencias - los efectos sobre el control político en el plano central - y trataremos de abordar algunos de esos desafíos combinando ideas teóricas y estudios empíricos. Utilizando como fondo el marco de los procesos de reformas y el contenido de éstas, nos preguntamos si la ola reformista está debilitando potencialmente el control democrático de los políticos sobre el servicio civil y sobre los procesos públicos de toma de decisiones y analizamos los efectos potenciales y reales que ejercen sobre el control político las reformas relacionadas con el modelo de la nueva administración pública.

Algunas de las principales interrogantes son: ¿Puede el modelo de la nueva administración pública considerarse en general como una reforma congruente que favorece la disminución del control político e incrementa la influencia administrativa y la autonomía institucional o es un paquete de reformas incongruentes, con elementos que apuntan en diferentes direcciones? ¿Qué consecuencias tiene para los procesos de toma de decisiones el prestar más atención a las consideraciones y valores económicos? ¿Está la devolución estructural de facultades ${ }^{2}$ debilitando el potencial de control político?; y, finalmente, ¿está la contratación causando que las relaciones político-administrativas se basen más en el rendimiento de cuentas individual y en las estrategias de adaptación que en las responsabilidades políticas colectivas?

En este trabajo hacemos énfasis primero en una perspectiva transformadora de las reformas administrativas que pone en tela de juicio la tesis de la globalización, tesis que subraya la difusión rápida y determinista de un modelo universal de reformas como lo es el de la nueva administración pública. Argumentamos que las doctrinas de dicho modelo se transforman cuando se enfrentan a las tradiciones históricoinstitucionales y al estilo de normatividad administrativa nacional de los diferentes países. Segundo, describimos las principales características del modelo de la nueva administración pública, argumentando que, en un plano general, el concepto tiene un enfoque unidimensional en la economía y la eficiencia, pero también que, en un plano más específico, existe un conflicto en el seno de ese concepto entre el control político-administrativo central y la autonomía administrativa e institucional "local". Tercero, ilustramos esta paradoja centrando nuestra atención en la devolución estructural de facultades y la contratación, dos características principales del modelo de la nueva administración pública. Cuarto, analizamos la relación entre el control político y la autonomía administrativa con respecto a la cuestión del rendimiento de cuentas y la responsabilidad, tratando de resumir algunos 
de los principales efectos negativos y positivos posibles del modelo de la nueva administración pública sobre la gobernanza política.

Para ilustrar nuestro análisis, mostraremos las diferencias entre algunas características de la reforma en tres países, Australia, Nueva Zelanda y Noruega, sin intentar compararlos de una manera amplia y sistemática ni entrar en detalles respecto a ciertos elementos de la reforma. Tanto Australia como Nueva Zelanda se embarcaron en un proceso de reforma sustancial entre 1983 y 1984, iniciado por los gobiernos laboristas, pero eligieron rutas un tanto diferentes en lo concerniente a la rapidez, alcance y contenido de las reformas al servicio civil, pues Nueva Zelanda adoptó un estilo "arrollador" más agresivo y exhaustivo, mientras que Australia eligió un rumbo más gradual y orientado hacia el consenso (Castles et al., 1996; Mascarenhas, 1996). En Noruega, las reformas comenzaron tardíamente y siguieron adelante con grandes reservas, la mayor parte del tiempo con el Partido Laborista en el poder, si bien adquirieron un poco más de velocidad a mediados de los años 90 (Lægreid y Roness, 1998; Olsen, 1996).

La base empírica de los ejemplos que utilizamos a manera de ilustración en los casos de Australia y Nueva Zelanda está formada por extensas reseñas críticas de los estudios existentes sobre las reformas, así como por entrevistas y reuniones con investigadores y servidores civiles. Los datos correspondientes a Noruega fueron tomados de varias fuentes, entre ellas estudios detallados sobre las reformas, pero la fuente principal fue una amplia encuesta hecha a alrededor de 2.500 entrevistados en 1996 del servicio civil central en puestos ejecutivos y más altos (Christensen y Lægreid, 1998a).

\section{Una perspectiva transformadora sobre la reforma administrativa}

Una manera de interpretar el modelo de la nueva administración pública es poner de relieve que se trata de un concepto o "fórmula" de modernización, preparada y difundida por patrocinadores internacionales del concepto, y que se está difundiendo alrededor del mundo y en los sistemas políticoadministrativos nacionales, ejerciendo un marcado efecto en las actitudes y el comportamiento de los responsables de tomar las decisiones (Røvik, 1996 y 1998). Tal interpretación puede basarse en un punto de vista determinista ambientalista (Olsen, 1992) que pone el acento en el hecho de que el modelo de la nueva administración pública es un conjunto de ideas reformistas que han sobrevivido a los procesos de selección y demostrado su fortaleza. La presión determinista del medio ambiente puede significar, ya sea que esas reformas son en realidad las más efectivas y eficaces, ya sea demostrar 
que el modelo de la nueva administración pública es un mito o "moda" que tiene un "predominio ideológico" como el paquete de reformas más apropiado y que se utiliza para aumentar la legitimidad del sistema político-administrativo (Meyer y Rowan, 1977).

Nosotros argumentaremos que los procesos de reformas públicas, como los relacionados con el modelo de la nueva administración pública, no se caracterizan por un simple ajuste de las actuales doctrinas internacionales sobre la administración. Evidentemente, los conceptos de la reforma son filtrados, interpretados y modificados a través de la combinación de dos procesos más cuya base es nacional. Uno de ellos lo integran la historia, la cultura, las tradiciones y la gobernanza políticoadministrativos nacionales, desarrollados de una manera evolutiva; y el otro lo constituyen las acciones efectivas emprendidas por los dirigentes políticos y administrativos para favorecer las metas colectivas mediante la planeación administrativa y una política administrativa nacional activa (Olsen, 1992; Olsen y Peters, 1996).

La perspectiva transformadora se pone de manifiesto a través de la combinación de las características internas y ambientales de la reforma para explicar por qué el modelo de la nueva administración pública puede tener efectos y consecuencias diferentes en distintos países (Christensen y Lægreid, 1998b). En un extremo, la presión del medio ambiente internacional para adoptar las reformas del modelo de la nueva administración pública puede tener efectos profundos sobre los sistemas nacionales, favorecidos por un liderazgo político-administrativo y la compatibilidad con las tradiciones histórico-culturales. En el otro, la presión del medio ambiente para adoptar las reformas puede producir pocos cambios y efectos, porque los dirigentes políticos y administrativos tratan conscientemente de detener o evitar las reformas debido a que no son compatibles con las normas y valores tradicionales (Brunsson y Olsen, 1993). Esos extremos corresponden a procesos de descontextualización, que ponen el énfasis en la idoneidad y armonía entre los conceptos de cambios ambientales y las necesidades internas, y en procesos de contextualización, que se enfocan en la singularidad de los sistemas nacionales y en la falta de compatibilidad con reformas producidas en el exterior, así como con los valores y normas de dichas reformas (Røvik, 1996).

Debemos ser realistas y admitir que existen razones para creer que, cuando se transfieren a los sistemas político-administrativos nacionales, los conceptos y procesos de reforma generados en el exterior son más complejos y tienen efectos y consecuencias más variados y ambiguos que los extremos que acabamos de esbozar. Los líderes políticos pueden utilizar pragmáticamente algunas porciones de las reformas generadas en el exterior o tratar de redefinir sus elementos ambiguos en el contexto nacional con el propósito de que armonicen con las metas instrumentales; 
o pueden manipular conscientemente las reformas como mitos y símbolos, aparentando ponerlas en práctica, pero sin tener realmente la intención de hacerlo, y tratar de promover su legitimidad a través de ambigüedades o separando el discurso de las decisiones y las acciones (Brunsson, 1989); o bien, pueden aceptar las reformas y dejar que las pongan en práctica los líderes administrativos, permitiendo así que los ajustes y modificaciones sean adecuadas para las características culturales institucionales (Røvik, 1998).

Dada la complejidad potencial mostrada por la perspectiva de la transformación, vemos que los efectos que ejercen las reformas relacionadas con el modelo de la nueva administración pública sobre el control político pueden apuntar en diferentes direcciones. Los políticos pueden tener la intención de mantener o fortalecer su poder y control valiéndose conscientemente de la ola reformista, ya sea instrumental o simbólicamente, ya sea de ambas maneras; pero también pueden perder el control al aceptar elementos de la reforma que debiliten su liderazgo, ya sea porque ésa es su intención o porque están bajo presión o porque no entienden los efectos y consecuencias de las reformas o porque tienen una idea falsa de las consecuencias culturales. Por lo demás, los efectos de las reformas del modelo de la nueva administración pública sobre el control político-democrático también pueden estar relacionados con la manera como los líderes administrativos definen o redefinen su papel y ponen en práctica las reformas.

La perspectiva transformadora centra su atención en las dimensiones ambientales externas y en las dimensiones instrumentales culturales y políticas internas para entender el fondo de las reformas, los rumbos tomados por éstas (su contenido) y los efectos experimentados y logrados a través del modelo de la nueva administración pública. Basándonos en esas dimensiones observadas en los tres países seleccionados, analizaremos los efectos potenciales y reales - qué efectos se esperaban según la teoría y cuáles fueron los resultados empíricos obtenidos - y cómo se relacionan esos efectos con la variedad de contextos de las reformas y con el contenido de éstas.

Las características ambientales plantean interrogantes respecto a la turbulencia y la inseguridad que generan la necesidad de introducir cambios sustanciales en el sector público o de adaptarse a los mitos internacionales de modernidad. Aparentemente, Nueva Zelanda y Australia, esta última en menor medida, sintieron que se encontraban en crisis económica y eso facilitó la presión para llevar a cabo reformas exhaustivas del servicio civil destinadas a reducir el Estado (Evans et al., 1996); las reformas económicas tenían que incluir al sector estatal, que representaba una gran proporción del PIB. Uno de los posibles efectos era el fortalecimiento del control del mercado a expensas del control político. Así, la presión del medio ambiente se definió como determinista, en una 
especie de reflexión sobre "el peor de los escenarios". En Australia, por ejemplo, se argumentó que, sin una "cirugía mayor", el país terminaría como una "república bananera" (Campbell y Halligan, 1992: 92; Melleuish, 1998: 80). Además, su pertenencia al grupo de países típicamente angloestadunidenses o "anglohablantes" podía hacer que fuera más fácil imitar los elementos de las reformas puestas en práctica en Estados Unidos y en el Reino Unido (Castles, 1989; Halligan, 1998; Hood, 1996).

En Noruega, por otra parte, no existía una crisis económica evidente que pudiera legitimar la puesta en práctica de reformas públicas exhaustivas, y la distancia respecto a los elementos de la reforma anglo-estadunidense era mayor. Un Estado intervencionista y planificador con un sector público más grande bajo un estrecho control político se consideraba como un medio adecuado para promover el bien común.

La primera de las dimensiones internas que explican potencialmente los procesos y efectos de las reformas está constituida por las tradiciones, normas y valores culturales que caracterizan a los sistemas político-administrativos. El contexto histórico-institucional de Noruega se caracteriza por una fuerte tradición estatista, homogeneidad de las normas y confianza mutua entre los líderes políticos y los administrativos; igualdad, cambios graduales, el contrapeso de muchas consideraciones y un menor énfasis de los factores económicos en el servicio civil, así como un estilo normativo de cooperación pacífica y de "revolución en cámara lenta", factores todos que llevan a creer que el modelo de la nueva administración pública tendría que ser puesto en práctica con mayor lentitud, con algunas modificaciones y con renuencia (Christensen, 1997; Christensen y Lægreid, 1998c; Christensen y Peters, 1999; Olsen, Roness y Sretren, 1982). Nueva Zelanda es también un país relativamente pequeño cuyo desarrollo se basa en algunos de los mismos valores que Noruega y cuyo Estado funciona como un vehículo colectivo para la acción popular, pero quizás está más polarizado, es culturalmente heterogéneo y cuenta con una tradición estatista más débil (Castles, 1993: 17; Boston et al., 1996: 10-11). Australia; por su parte, es un país más grande, federal y más heterogéneo, con tradiciones culturales mucho más diversas y una mayor tensión entre los líderes políticos y los administrativos, lo que hace más probable que ciertas áreas del sistema sean compatibles con las reformas orientadas hacia el modelo de la nueva administración pública. A diferencia de Noruega, durante algunos períodos de los años 70, la desconfianza caracterizó las relaciones de los gobiernos laboristas de Australia y Nueva Zelanda con sus servidores civiles (Mascarenhas, 1990). Australia y Noruega, por otra parte, parecen ser más similares que Nueva Zelanda en lo concerniente tanto a la importancia política de los acuerdos corporativistas de cooperación tradicionales como a las estrechas relaciones entre los partidos laboristas y los sindicatos de trabajadores (Olsen, 1983). 
La segunda dimensión interna, las condiciones políticoinstrumentales, también ha sido diferente en los tres países. En Australia y Nueva Zelanda, sus sistemas de dos partidos al estilo Westminster hacen más probable que las reformas puedan ponerse en práctica con mayor energía que en Noruega que, con su sistema pluripartidista y sus gobiernos minoritarios, se caracteriza más por las negociaciones y la turbulencia parlamentaria (Campbell y Halligan, 1992: 5-6; Christensen y Peters, 1999). En Nueva Zelanda, en particular, el potencial de control se ha relacionado en gran medida con una forma de gobierno unitaria, un parlamento de una sola cámara, un Poder Ejecutivo fuerte y una gran disciplina partidista en el Parlamento (Boston et al., 1996: 43-50); además, el sistema al estilo Westminster está probablemente más expuesto que el sistema pluripartidista de Noruega, cuyo primer ministro es formalmente débil, a que los líderes políticos fuertes sean los patrocinadores de la reforma, aun cuando también se argumenta que su poder depende del poder colectivo de un gabinete concertado. A diferencia de los otros dos países, Australia es un sistema federal; y el federalismo podría generar una mayor variedad entre los estados y más posibílidades de que la reforma se inície desde abajo, antes bien que desde arriba.

La combinación de los tres factores en la perspectiva de la transformación pone de manifiesto ciertas variaciones entre los tres países. Nueva Zelanda está siguiendo el camino más drástico hacia la reforma debido a la combinación de una crisis económica y una "dictadura electoral" (Mulgan, 1992), mientras que la tradición cultural hace que la jornada sea más problemática en algunos sentidos. El apoyo popular a un nuevo sistema de elecciones, por ejemplo, considerado por muchos como una reacción a las reformas, hace que en la actualidad sea poco probable una reforma más exhaustiva. En Australia, las reformas al modelo de la nueva administración pública se están iniciando en un contexto de tensión y conflictos entre los líderes políticos y el servicio civil y de experimentación de la reforma en algunos estados, emprendida con energía por el primer ministro como patrocinador político (Campbell y Halligan, 1992). Pero el camino adoptado es más cauteloso que el emprendido en Nueva Zelanda, debido a la mayor heterogeneidad y a las características corporativas. En Noruega, las reformas relacionadas con el modelo de la nueva administración pública comenzaron tarde y, cuando finalmente aparecieron, lo hicieron de manera gradual y con renuencia, debido a la poca compatibilidad cultural ya la relativa debilidad del poder político-administrativo; además, los agentes más importantes del cambio fueron los servidores públicos y no los dirigentes políticos (Christensen, 1997; Cristensen y Lægreid, 1998c).

Cuando se analiza el intercambio entre la gobernanza política y la autonomía administrativa, es importante distinguir entre el cambio del 
sistema mismo y el nuevo sistema en funcionamiento. Una posible consecuencia paradójica es que el proceso de la reforma en Nueva Zelanda y Australia parece estar bajo un estricto control político, pero, en la práctica, el nuevo sistema podría haber debilitado el control político en favor de la autonomía administrativa. En Noruega, en cambio, el proceso de reforma estuvo más bajo el control administrativo, pero es probable que las reformas puestas en práctica hayan debilitado en menor grado el control político.

\section{Características principales del modelo de la nueva administración pública}

Antes de analizar los efectos que las reformas relacionadas con el modelo de la nueva administración pública ejercen sobre el control político, esbozaremos algunas de las principales características de ese modelo y examinaremos las variaciones de su contenido en los países estudiados. En primer lugar, describiremos las ideas fundamentales del modelo de la nueva administración pública y, en segundo lugar, daremos una explicación de las tensiones inherentes al concepto de la nueva administración pública.

\section{La primacía de las normas $y$ los valores económicos}

La principal característica del modelo de la nueva administración pública es su énfasis en las normas y los valores económicos, esto es, tanto el concepto como la ola reformista y los programas de reformas relacionados con él son, a ese respecto, unidimensionales. Esto implica una especie de "preponderancia ideológica" y que muchas de las normas y valores tradicionalmente legítimos del sector público se consideren subordinados a las normas económicas, lo que hace más evidentes los conflictos y tensiones entre las diferentes normas y valores (Boston et al., 1996: 354). En el modelo de la nueva administración pública, esa preponderancia se relaciona también con las contundentes opiniones respecto a la manera como las normas y valores económicos ejercen ciertos efectos sobre otras consideraciones, lo cual significa que el hecho de hacer énfasis en la eficiencia entraña transformaciones tanto de la organización formal del sector público como de los procedimientos, la pericia necesaria y la relación con el sector privado.

Cuando se dice que las reformas del modelo de la nueva administración pública son típicamente "teóricas", por ejemplo en Nueva Zelanda, lo que a menudo se quiere decir es que las teorías económicas son predominantes. Ejemplos de ello son las teorías sobre la toma de decisiones en el sector 
público, los modelos del agente principal y los modelos de los costos de transacción (Boston et al., 1991 y 1996: 17-25). Con base en esos modelos, se considera que las relaciones entre los actores del sistema político-administrativo constituyen juegos estratégicos entre actores racionales que tratan de lograr que este sistema sea más eficiente, racionalizado y congruente (Boston et al., 1996: 3; Evans et al., 1996). En esos modelos económicos parece considerarse que las metas ambiguas, las estructuras formales complejas y las normas culturales compuestas de un servicio civil complejo son síntomas de "enfermedad" y no características distintivas fundamentales del sector público. Por otra parte, los críticos de esos modelos hacen notar que ese tipo de pensamiento es simplista, pues disminuye la importancia de la ética del sector público y de las restricciones de la cultura institucional, y que no ha demostrado ser tan fructífero cuando tiene que enfrentarse a la vida cotidiana del sector público.

Examinaremos principalmente la manera como el nuevo predominio del pensamiento económico sobre el sector público, representado por el modelo de la nueva administración pública, se relaciona con las transformaciones de la estructura, los procedimientos y la cultura de los sistemas político-administrativos, centrando nuestra atención en la devolución estructural de facultades y en la contratación. Una de las interrogantes principales es la manera como los elementos de la reforma ejercen sus efectos sobre el control político-administrativo de los sistemas y cuáles son las consecuencias que tienen para dicho control.

\section{El carácter híbrido del modelo de la nueva administración pública}

Aun cuando el modelo de la nueva administración pública cultiva ciertos valores y objetivos económicos, el concepto es vago y tiene muchas facetas; entre ellas, diferentes elementos que abarcan una especie de "canasta de compras" para los reformadores de la administración pública (Hood, 1991; Pollitt, 1995). Los principales componentes del modelo de la nueva administración pública son: una administración profesional práctica que permite el control activo, visible y discrecional de las organizaciones por personas que tienen "libertad para administrar"; normas explícitas de rendimiento y un mayor énfasis en su control; y más competencia, contratación, transferencia de poder estructural, desagregación de unidades y técnicas de administración del sector privado.

Las tensiones que surgen del carácter híbrido del modelo de la nueva administración pública, que combina la teoría de la organización económica con la teoría de la gerencia, fueron expuestas por Aucoin ( 1990 ) y Hood (1991). Esas tensiones son el resultado de las tendencias a la centralización inherentes al contractualismo, en oposición a las tendencias del gerencialismo 
a la devolución de poder. El primer conjunto de ideas proviene de la teoría de la organización económica, como la toma de decisiones pública, y la teoría del agente principal, cuya atención se centra en la primacía del gobierno representativo sobre la burocracia. Una de las lecciones de este paradigma es que el poder de los dirigentes políticos debe fortalecerse en contra de la burocracia. Ahora bien, esa concentración de poder requiere que se preste atención a la centralización, la coordinación y el control, y los arreglos contractuales son uno de los principales mecanismos para alcanzar esa meta.

El segundo conjunto de ideas proviene de la escuela de pensamiento "gerencialista", que centra su atención en la necesidad de restablecer la primacía de los principios gerenciales en la burocracia. Su concentración en el incremento de la capacidad de los gerentes para emprender acciones requiere que se preste atención a la descentralización, la devolución estructural de facultades y la delegación de responsabilidades. Así, el modelo de la nueva administración pública es una "espada de dos filos" que prescribe tanto la centralización como la devolución estructural de facultades. En este artículo analizaremos esa paradoja, centrando nuestra atención en las medidas reformistas destinadas a incrementar la libertad - autonomía a través de la devolución estructural de facultades - y en las destinadas a aumentar el control centralizado a través de diferentes tipos de contratos.

Nosotros suponemos que el modelo de la nueva administración pública se inclinará más hacia la devolución estructural de facultades que hacia la centralización, porque la tendencia del contractualismo a la centralización no es totalmente clara. El contractualismo favorece una mayor competencia, lo cual debilita potencialmente el control jerárquico central (Keaudern y Van Mierlo, 1998). Por otra parte, el contractualismo puede incrementar el liderazgo administrativo a expensas del liderazgo político; en Nueva Zelanda, por ejemplo, los contratos son diseñados y supervisados por unidades especializadas en el servicio civil, mientras que los políticos prácticamente no intervienen. Estos aspectos del contractualismo lo hacen más similar al gerencialismo y a la devolución estructural de facultades.

Según la Organización para la Cooperación y el Desarrollo Económicos (OCDE, 1995 y 1996a), el modelo de la nueva administración pública representa un cambio de paradigmas global relacionado con el control y la organización del servicio público. Nosotros ponemos en tela de juicio esta tesis de convergencia y sostenemos que los casos de Noruega y Nueva Zelanda ilustran la divergencia de las reformas del sector público. Aun cuando, en cierto grado, ambos países presenten sus reformas en términos similares y sustenten las mismas doctrinas administrativas generales, un examen más profundo revela una variación considerable entre esos países (Cheung, 1997; 
Hood, 1995). Nuestra tesis es que Noruega se ha mostrado moderada y renuente en cuanto a las reformas: se ha inclinado muy poco por el contractualismo y la competencia, mientras que la devolución estructural de facultades ha sido moderada. Nueva Zelanda, por su parte, se ha mostrado más radical y agresiva en la aplicación de la reforma: ha habido un alto grado tanto de devolución estructural de facultades como de contractualismo y competencia. Australia se encuentra más o menos entre los otros dos países, pero significativamente más cerca de Nueva Zelanda que de Noruega, pues se vale de los contratos en los planos federal y estatal superiores, mientras que recurre a la devolución estructural de facultades y la competencia en una medida ligeramente menor.

En Australia y, en cierto grado, en Noruega, los reformistas gubernamentales preconizan la necesidad de "dejar que los administradores administren"; a través de arreglos de devolución estructural de facultades, los administradores deben obtener un gran poder discrecional y estar en "libertad de administrar". Los reformistas creían que los administradores sabían con exactitud qué debían hacer, pero que las reglas, procedimientos y estructuras existentes les creaban barreras para hacerlo. La idea era que el hecho de centrar la atención de los administradores en los problemas que requerían solución, y entonces darles la flexibilidad para resolverlos, fomenta el desarrollo de organizaciones que pueden adaptarse con mayor rapidez y gobiernos que funcionan mejor. Se han concentrado en la devolución estructural de facultades y en el incremento de las habilidades de sus administradores a través de la capacitación y mediante la remodelación del sistema del servicio civil para estimular el rendimiento. El hecho de que el servicio público australiano haya adaptado el discurso de la administración gerencial en los años 80 puede considerarse como una revolución cultural (Yeatman, 1987); en Noruega, asimismo, los líderes hablan del servicio público en función de la administración gerencial en un grado mucho mayor que antes. El fondo de tales tendencias parece ser un tanto diferente en esos dos países. A Australia la preocupaban más los papeles políticos y administrativos bien definidos como un instrumento para debilitar la burocracia, mientras que, en Noruega, esa cuestión parece considerarse como algo más práctico para incrementar la capacidad de los líderes políticos, aunque se subraya que los líderes políticos y administrativos sí comparten normas y valores. En los inicios del proceso de la reforma, a Australia también la preocupaba la transformación de la administración financiera central, inspirada por los actores privados (Guthrie y Parker, 1998). La manera como Australia está poniendo en práctica el modelo de la nueva administración pública es más pragmática que la manera como lo hizo Nueva Zelanda en los años 80 y más orientada hacia la administración gerencial; pero las similitudes entre los dos países se han incrementado en los 90 debido al énfasis más pronunciado en los elementos 
del mercado: la competencia, la subcontratación y la privatización (Halligan, 1998: 157; McIntosh et al., 1997; Wettenhall, 1998).

A diferencia de Australia, Nueva Zelanda ha puesto en práctica agresivamente una política de "hacer que los administradores administren". Los reformadores creían que la única manera de aumentar el rendimiento gubernamental era modificar los incentivos de los administradores públicos sometiéndolos a las fuerzas del mercado y a contratos. Así, a los administradores de alta jerarquía se les contrata por tiempo determinado, se les paga de acuerdo con su rendimiento y, si su trabajo no está a la altura, pueden ser despedidos (Kettl, 1997: 448). Los contratos por trabajo y rendimiento individuales han reemplazado al sistema del servicio civil basado en las reglas y los procesos. Este estricto contractualismo hace diferentes las reformas de Nueva Zelanda de las emprendidas en Noruega y Australia (Schick, 1998). Los acuerdos de rendimiento desplazan a la antigua ética de la confianza y la responsabilidad y se espera que cada funcionario ejecutivo rinda cuentas sobre los resultados esperados. Esos acuerdos semejantes a los contratos se han extendido al asesoramiento en cuestiones normativas, de tal manera que los ministros pueden optar por obtener información e ideas de asesores privados y otras fuentes externas (Boston et al., 1996: 122-125).

Por lo general, el modelo de la nueva administración pública depende en gran medida de la combinación de la teoría de la microeconomía con las prácticas gerenciales, y muchos de los elementos importantes y problemáticos de la reforma, como las relaciones entre los administradores públicos y los funcionarios electos, reflejan las tensiones potenciales en la manera como están combinados. A través de la devolución estructural de facultades y la contratación, el modelo de la nueva administración pública ha buscado separar más claramente la formulación de las políticas de la administración y aplicación de estas últimas. Los responsables de la formulación de las políticas elaboran las políticas, para después delegar en los administradores su implementación y hacerlos responsables de ellas mediante contratos. Más adelante analizaremos si eso representa un cambio bien equilibrado o si, en realidad, es un sistema que debilita el control político.

\section{La devolución de poder: ¿más autonomía y poder para los administradores?}

La devolución de poder puede adoptar muchas formas, pero una de las ideas principales es fortalecer el poder discrecional de los administradores y otorgar más autonomía a los planos y agencias subordinados a la 
administración pública (OCDE, 1996b; Grønlie y Selle, 1998). En esta sección centraremos nuestra atención en la devolución estructural de facultades, que incluye la separación de las funciones políticas de las administrativas, la separación estructural de las funciones administrativas que tradicionalmente han estado organizadas juntas y la especialización interorgánica vertical, es decir, la creación de nuevas unidades subordinadas que lleven a cabo las actividades comerciales.

\section{La separación de las funciones políticas y administrativas}

La manera de pensar desde el punto de vista de la economía de los defensores del modelo de la nueva administración pública apunta hacia un axioma casi generalmente aceptado en ciertos círculos: es más eficaz separar las funciones políticas y administrativas que tenerlas integradas, como había sido tradicionalmente en la mayoría de los países (Boston et al., 1996: 4). La argumentación consiste en que el hecho de dividir esos elementos hace más evidente que se trata de funciones diferentes con actores distintos: que los políticos deberían establecer las metas y los servidores públicos implementar las políticas. A menudo existe también una idea de descentralización relacionada con esa argumentación; a saber: que el proceso de la toma de decisiones debería estar más cerca de los clientes, lo que introduce cierta ambigüedad respecto a si eso está destinado únicamente a las decisiones administrativas menos importantes o no. Nueva Zelanda, por ejemplo, ha dejado atrás un modelo de integración, en el que los ministros y los servidores públicos de alta jerarquía luchan por alcanzar una relación de cooperación que reconozca sus intereses conjuntos, para adoptar un modelo comprador-productor, en el que los papeles políticos y administrativos están más claramente separados desde el punto de vista institucional.

Una argumentación que sirve de apoyo para establecer una división más marcada entre la política y la administración es que una solución integrada hace que los políticos sean vulnerables a la influencia y presión de los servidores públicos, que éstos han amenazado con invadir la esfera política y que una separación más estricta de las funciones hace que el control del servicio civil sea más fácil. Tal fue el fondo para la reforma en Australia a principios de los años 80 (Campbell y Halligan, 1992). Escindiendo partes del servicio civil, el control político a distancia llegaría a ser menos ambiguo y más efectivo. Un argumento adicional fue que la separación podía incrementar al mismo tiempo tanto el control político como la discrecionalidad administrativa, generando así mejores políticas y servicios en el sector público. 
La discusión de los efectos de la separación de las funciones sobre el control político saca a la luz muchos argumentos diferentes. En primer lugar, muy pocos profesionales o investigadores argumentarían que los políticos y los servidores públicos deben desempeñar las mismas labores; pero, dicho esto, existen muchas maneras de definir sus funciones, desde burócratas convertidos en políticos, en un extremo, hasta servidores públicos tecnócratas y apolíticos, en el otro (Christensen, 1991).

En segundo lugar, no es fácil aceptar que la solución diferenciada incrementaría al máximo la influencia tanto de los políticos como de los servidores públicos; en lugar de ello, se podría argumentar convincentemente: que las transformaciones orgánicas formales siempre inclinan el patrón de influencia en una dirección o la otra; lo cual es también una de las razones por las que los procesos de reorganización pública se caracterizan a menudo por el conflicto (Christensen y Lægreid, 1998d).

En tercer lugar, la única diferencia importante entre una solución integrada y una segregada es que la primera combina un control potencialmente firme del servicio civil con un acceso fácil al liderazgo político para los burócratas, mientras que la segunda combina un control potencialmente débil del servicio civil con un reducido acceso al liderazgo político para los burócratas (Egeberg, 1989). Esto ilustra que cualquier solución estructural tiene ventajas y desventajas.

Una cuestión de capital importancia relativa al control político parece ser también el saber si entre los líderes políticos y los administrativos existe acuerdo en lo relacionado con las prioridades, las normas y los valores. A este respecto, parece ser políticamente menos problemático separar las funciones políticas de las administrativas, por ejemplo en el caso de Noruega, donde ese tipo de coherencia es más bien alto (Christensen, 1991; Christensen y Egeberg, 1997).

\section{La separación estructural de las funciones administrativas}

Otra forma de la devolución estructural de facultades, encontrada en muchos países que han puesto en práctica una reforma relacionada con el modelo de la nueva administración pública, es la separación estructural de las funciones administrativas que tradicionalmente han estado organizadas juntas, como el asesoramiento en cuestiones políticas, las tareas de regulación, las funciones de propiedad, las de control y las de compradorproveedor, lo cual puede considerarse como una especie de resultado de una división más marcada entre las funciones políticas y las administrativas. Nueva Zelanda es el ejemplo más típico de ese tipo de cambio estructural, cuyo resultado ha sido un gran número de agencias y departamentos centrales y que las entidades de la Corona, incluidas las empresas de 
propiedad del Estado, adopten el principio de las organizaciones con un solo propósito o una sola tarea (Boston et al., 1996: 56-66 y 77-80). Los argumentos en favor de esta solución son que mejora la efectividad y la eficiencia a través de una definición más clara de las funciones administrativas y que evita los traslapes y la combinación ambigua de funciones que difuminan las líneas de mando y autoridad.

Vale la pena hacer notar que Australia eligió una solucion más integrada que Nueva Zelanda en las cuestiones relativas a la "maquinaria de gobierno" a través de la creación de departamentos gigantescos a finales de los años 80. El resultado potencial de ello, a pesar de las medidas adoptadas para separar las funciones políticas y administrativas unos años antes durante el mismo decenio, es la centralización (Stewart y Kimber, 1996). En Noruega, por otra parte, la tendencia durante los años 90 ha sido a separar las funciones de supervisión y regulación de las de producción y servicio mediante el establecimiento de autoridades de control independientes.

Un efecto posible de la profunda especialización administrativa de las funciones es el incremento de la necesidad de coordinación, porque hay una mayor fragmentación del sistema. Otro efecto podría ser que las nuevas unidades especializadas crezcan al agregarles tareas que perdieron con la especialización; por ejemplo: que a las unidades de compras se les añadan funciones de asesoramiento en cuestiones normativas. Todo ello podría llevar a un incremento del número de servidores públicos y de recursos utilizados, en oposición a lo que era la intención original. Nueva Zelanda, al igual que otros cuantos países, redujo el número de servidores públicos en el plano central (Gregory, 1998a), esto es, avanzó en dirección opuesta a la indicada por este escenario; pero la disminución del tamaño puede entrañar una menor capacidad para controlar y coordinar las instituciones y empresas subordinadas creadas a través de la devolución estructural de facultades.

\section{La especialización interorganizacional vertical}

Una tercera forma de devolución estructural de facultades relacionada con el modelo de la nueva administración pública y combinada con las otras dos mencionadas es la tendencia hacia la especialización interorganizacional vertical. Muchos países están cambiando sus principales formas organizacionales político-administrativas o mudando unidades a formas organizacionales que se encuentran más lejos del liderazgo político central.

Los argumentos que se esgrimen desde el punto de vista de la economía para justificar esa devolución estructural de facultades se basan en una especie de lógica determinista. La presión mundial para que la 
cooperación y la competencia adopten nuevas formas es en el sentido de que haya mayor competencia en los mercados y se lleven a cabo vastos procesos de cambio a los que un país o unidad administrativa por si solos no pueden hacer frente fácilmente. Tienen que adaptarse al desarrollo haciendo hincapié en una mayor devolución estructural de las funciones comerciales para hacer frente al aumento de la competencia. Lo anterior es también un reflejo del axioma que establece que la política y los negocios deben estar separados y que los actores privados son mejores actores en el mercado que los públicos; para el sector público, consecuentemente, la manera más efectiva de hacer negocios es, ya sea crear formas organizacionales que se ocupen más sistemáticamente de las funciones comerciales o dejar que los actores privados absorban algunas de las funciones comerciales del sector público.

Existen muchas variedades de esa forma de la devolución estructural de facultades. En algunos países, como Noruega, tanto los departamentos como las agencias están otorgando gradualmente una mayor autoridad y autonomía en la toma de decisiones a organismos subordinados independientes $\mathrm{y}$, dentro de los propios departamentos y agencias, a niveles inferiores de administración (Lægreid y Roness, 1998). Algunas unidades administrativas han sido reorganizadas como fundaciones, mientras que otras han sido transformadas en compañías de propiedad estatal. La argumentación es en el sentido de que esa clase de devolución estructural de facultades mejorará tanto la competitividad como el método de gobierno. En los años 90, tal evolución puede considerarse como un dispositivo para un Estado defensivo (Grønlie, 1998). Algunas de las agencias cuya personalidad jurídica ha sido transformada eran muy grandes; entre ellas: la compañía telefónica nacional, el servicio postal y los ferrocarriles estatales. Cuando, en una encuesta, se planteó la pregunta acerca de la importancia de cambiar la estructura interorgánica en el sentido indicado, sólo $25 \%$ de los servidores públicos noruegos de los ministerios y las agencias centrales atribuyeron una gran importancia a su propio campo de trabajo, lo cual indica que la reforma ha sido gradual y que ha habido reacciones de renuencia (Christensen y Lægreid, 1998a).

La combinación de los valores económicos con la devolución estructural de facultades a través de la especialización interorganizacional vertical se puede observar con mayor claridad en las reformas puestas en práctica por Nueva Zelanda. En las primeras etapas del proceso de reforma, se estableció que el gobierno no debería participar en actividades que pudieran ser desempeñadas con más efectividad por organizaciones no gubernamentales (Boston et al., 1996: 4). En primer lugar, ello significó que los aspectos económicos o comerciales de las políticas públicas pasaran a primer plano. En segundo lugar, implicó que esos aspectos tuvieran que ser diferenciados de otros, como las consideraciones sociales y políticosectoriales más generales. En tercer lugar, definió al gobierno como un 
actor que no está bien equipado para llevar a cabo actividades comerciales.

Y, en cuarto lugar, finalmente, llevó a la devolución estructural de las actividades comerciales y a la privatización.

La argumentación en contra de algunos de los argumentos económicos que sirven de apoyo a la devolución estructural de facultades podría ser que las funciones políticas y comerciales han estado integradas durante largo tiempo en muchos países sin grandes problemas, que el sector público gana mucho dinero con sus actividades comerciales y que éstas se deberían mantener con propósitos colectivos y que es importante que el sector público controle y regule algunas de las actividades económicas, incluso mediante la propiedad. Por otra parte, está la cuestión de saber si el sector privado es más eficiente que el público. Algunos argumentan que eso es imposible de establecer, puesto que las organizaciones públicas tienen que hacerse cargo de consideraciones más complejas, mientras que otros ponen de relieve el hecho de que la eficiencia tiene más que ver con el tamaño y complejidad estructural de las organizaciones que con la distinción entre lo público y lo privado (Allison, 1983).

\section{La devolución estructural de facultades y el control político}

Una de las ideas principales relacionadas con la devolución estructural de facultades es que las actividades políticas y comerciales deben estar separadas orgánicamente, para dar lugar al establecimiento de formas orgánicas con menos control político, tanto formalmente como en la realidad. Las reformas de ese tipo se aprecian principalmente, por ejemplo, en el sector de las comunicaciones. Las transformaciones son impulsadas por una combinación de actores que puede variar según los países: líderes políticos y administrativos convencidos de que el incremento de la competencia da impulso simultáneamente tanto al control como a la eficiencia, líderes institucionales a quienes les gustaría que aumentara la discrecionalidad, así como que se contara con un perfil más comercial y actores privados que ven nuevas opciones de hacer negocios.

Esta manera de pensar se relaciona con la consigna de "dejar que los administradores administren", con lo que se quiere decir que los administradores gocen de discrecionalidad y que no haya demasiada interferencia cotidiana de los líderes políticos. Pero, ¿qué significa esa consigna en lo referente al control político? Puede significar que, a través de una división marcada entre la política y la administración, los principales ejecutivos son mejores para administrar y, por lo tanto, debe dárseles la discrecionalidad y la oportunidad para hacerlo, reduciendo de ese modo la carga sobre el liderazgo político y aumentando el control político; pero también podría argumentarse que la consigna refleja una tendencia contraria a la política 
que potencialmente debilitaría el control político. "Dejar que los administradores administren" podría significar que los administradores estén adquiriendo más recursos, tareas y responsabilidad, haciendo menos legítimo que el político interfiera en sus asuntos.

Un efecto evidente del incremento de la transferencia estructural de las funciones comerciales sobre el sector público es un sector público más racionalizado, debido a las reducciones de la fuerza de trabajo en las empresas públicas y a la privatización (Gregory, 1998b). Otro efecto es el aumento de la complejidad estructural o de formas híbridas, debido a la existencia de nuevas combinaciones de intereses políticos y comerciales incorporadas en las nuevas unidades públicas.

Ahora bien, ¿resulta debilitado el control político por el aumento de la devolución estructural de facultades, independientemente de que ésta sea eficaz? Uno de los principales argumentos para responder afirmativamente a esta pregunta es que la devolución estructural de facultades incrementa la distancia entre el liderazgo político y las unidades y planos inferiores subordinados de la administración (Egeberg, 1989). Esta lógica se basa en la noción de erigir nuevas barreras o límites estructurales. Las encuestas llevadas a cabo en el servicio civil de Noruega han demostrado, por ejemplo, que los servidores públicos de las agencias centrales fuera de los ministerios, a diferencia de los burócratas de los ministerios, consideran que las señales y las consideraciones políticas son significativamente menos importantes para la toma de decisiones (Christensen y Egeberg, 1997; Christensen y Lægreid, 1998a). Cuanto más separados estructuralmente estén los servidores públicos del liderazgo político, tanto mayor relativamente será la importancia de otras señales de decisión — como la eficiencia relacionada con los costos, las normas profesionales, los intereses de los clientes etc.,-, lo cual significa que los actores de las empresas públicas y otras unidades comparables prestarán aún menos atención a las señales políticas. Un informe sobre la propiedad pública en Noruega indica que, aun cuando formalmente se supone que las compañías públicas deben tomar en consideración las señales políticas generales o sectoriales, en realidad cada vez prestan más atención a los intereses comerciales (Statskonsult, 1998).

Por consiguiente, la principal lección es que la devolución estructural de facultades significa la disminución de la capacidad y de la autoridad de control centrales y que las unidades subordinadas, en particular las orientadas hacia el mercado, presten menos atención a las consideraciones políticas. Existe la tendencia a definir la participación política en las empresas públicas como una interferencia inapropiada en los asuntos comerciales.

Una explicación más detallada de este tipo de razonamiento es que incluso las actividades comerciales del sector público están sujetas al control 
político y que del liderazgo depende el politizar la función de esas actividades y desarrollar su control activo, lo cual podría hacerse mediante el nombramiento político de los líderes de las agencias o mediante un empleo más activo de los diferentes instrumentos de control, como las leyes y las reglas, los consejos de administración, la asamblea general anual o el contacto informal. Un ejemplo de un mecanismo que genera más atención a las señales políticas es la regla de Nueva Zelanda, que establece que los desacuerdos entre el gobierno y los consejos de administración de las empresas de propiedad estatal deben ser enviados al parlamento para su discusión y arbitraje.

Debido a problemas de capacidad, la propiedad pública activa de las actividades comerciales depende muy a menudo del control que ejercen los servidores públicos de más alta jerarquía a nombre de los líderes políticos. Potencialmente, ello podría debilitar el liderazgo político, ya sea porque se esté dando una base de poder independiente a los burócratas de más alta jerarquía, ya sea porque las corporaciones públicas hagan alianzas con el liderazgo administrativo.

Boston et al., (1996: 13,87-89 y 353-355) argumentan que la devolución estructural de facultades ha tenido una especie de efecto doble en Nueva Zelanda. Por una parte, se dice que es eficaz la separación de las funciones no comerciales de las comerciales, puesta de relieve en el establecimiento de empresas públicas (Evans et al., 1996); y, por la otra, las entidades de la Corona, en competencia con los actores privados, han provocado que el control y la coordinación políticos sean más problemáticos y las líneas de autoridad más ambiguas, lo cual ha hecho más difícil garantizar los intereses colectivos. A lo anterior se añaden los costos del cambio, que en general han sido altos.

Nueva Zelanda es una especie de caso extremo en lo que respecta al cambio estructural, porque decidió combinar una marcada especialización horizontal con una marcada especialización vertical. Por su parte, Australia muestra un perfil similar en lo concerniente a la devolución estructural de facultades, pero eligió otra solución horizontal, mucho más integrada, en lo concerniente a las cuestiones de la "maquinaria de gobierno": estableció 16 departamentos principales, los denominados "megadepartamentos", y esa característica dio apoyo a la política de Hawke de fortalecimiento de los aspectos integrantes del gabinete (Campbell y Halligan, 1992: 16-20). En comparación con una solución más fragmentada, probablemente eso puede haber fortalecido la influencia del liderazgo político, tanto en lo que respecta a los servidores públicos de mayor jerarquía de las agencias y departamentos centrales como en cuanto contrapeso a las instituciones y entidades comerciales subordinadas; por otra parte, en cuanto instrumentos de generación de políticas, los departamentos gigantescos constituyen unidades cuyo control resulta complejo. 
Noruega eligió un curso más semejante al de Australia que al de Nueva Zelanda para la reforma estructural. Ha puesto un mayor énfasis en la especialización horizontal moderada de los ministerios, si bien no ha hecho nada que se parezca a los departamentos gigantescos. En lo que respecta a la devolución estructural de facultades, Noruega ha sido más renuente que Australia y Nueva Zelanda, lo cual quizás ha dado como resultado un énfasis relativamente mayor en el control y la centralización políticos que en los otros dos países.

A través de las reformas, a Australia se le ocurrió el concepto de "gerencia política", lo que indica el deseo de combinar el control político con la administración gerencial, la centralización con la descentralización y la devolución estructural de facultades (Campbell y Halligan, 1992: 3941 y 203). Un análisis de la devolución estructural de facultades practicada en Australia durante una de sus primeras etapas que centra la atención en la reforma de la administración presupuestal y financiera, indica que ese país se las ha arreglado para combinar una mayor flexibilidad y una mayor devolución estructural de facultades con un mejor control central (Keating y Holmes, 1990). El fortalecimiento del liderazgo político se inició en los años 70 con más recursos para el gabinete y los ministros, asesoramiento alternativo en cuestiones normativas, más apoyo de los partidos políticos, politización del nombramiento de los servidores públicos de mayor jerarquía y un mayor énfasis en las prioridades y directrices políticas, mientras que en los años 80 se produjo el desarrollo de una "identidad corporativa" más marcada y de más estrategias colectivas y se prestó más atención a una administración de los recursos y el personal más cercana al liderazgo político (Halligan, 1996). Los elementos gerenciales fueron evidentes en el establecimiento de un servicio ejecutivo de alta jerarquía, los cambios en la administración financiera, la asignación de fondos presupuestarios para programas y la supervisión de la eficiencia. Lo anterior se combinó con una mayor devolución estructural de facultades de los departamentos principales a los departamentos de proyectos y más abajo en la jerarquía, ejemplificada por el incremento de la comercialización de las actividades públicas y por la privatización en los años 90 (Guthrie y Parker, 1998). En conjunto, todo ello dio como resultado un cambio hacia la cultura gerencial.

La devolución estructural de facultades plantea cuestiones acerca del desarrollo de sistemas de control. ¿Cómo deben diseñarse los sistemas de control cuando el liderazgo político está descentralizando la autoridad para la toma de decisiones o la autoridad para administrar e implementar las políticas, ya sea a través de la devolución estructural de facultades o no? Una solución es emplear sistemátic amente las leyes, reglas y reuniones formales como instrumentos para controlar las unidades y actividades subordinadas. Una de las ventajas de ello es que puede modificar los problemas de capacidad, pero una de sus desventajas es que con frecuencia 
esos sistemas son en realidad instrumentos de control más formales que reales y otra es que quienes pueden controlar tales sistemas son principalmente los líderes administrativos. Esto implica que predominaría el control profesional, solución que sería más tranquilizadora si las normas y valores políticos y profesionales fuesen compatibles, pero que sería menos tranquilizadora si hubiese conflictos y grietas en los sistemas. Otra solución al problema del control es la subcontratación, la cual abordamos ahora.

\section{La subcontratación: ¿instrumento para un mayor control político?}

El modelo de la nueva administración pública ha abierto la puerta a una mayor competencia entre los sectores público y privado y, dentro del sector público, como un reflejo de las normas y valores económicos más importantes. El tipo de competencia más común y generalizado es el que se basa en la devolución estructural de facultades, fenómeno que acabamos de analizar. En muchos países, el precio que debe pagarse por una mayor devolución estructural de facultades y una mayor flexibilidad y por el hecho de que los administradores tengan más autonomía y poder discrecional es tener un sistema de control jerárquico más rígido mediante el recurso generalizado de la subcontratación. Se supone que, a través de los contratos, los líderes políticos especifican más claramente las metas y objetivos, y que el rendimiento se debe controlar mediante el empleo de indicadores cuantitativos para supervisar los resultados y medir la eficiencia. El explosivo incremento de las auditorías entraña elementos de centralización potencialmente fuertes e implica una atención cada vez más centrada en la "administración como Dios manda", formal y externa a expensas de las más tradicionales formas de control internas e informales basadas en la confianza (Power, 1994).

El concepto integrado del modelo de reforma administrativa de Nueva Zelanda es el gobierno por contrato (Schick, 1998). La mayoría de los elementos de la reforma han sido diseñados para que las relaciones entre, por una parte, el gobierno y los ministros y, por la otra, las entidades subordinadas, incluidas las instituciones y cada uno de los líderes, sean cada vez más semejantes a las contractuales. Nueva Zelanda ha hecho todo lo posible por crear las condiciones adecuadas para que se negocien y se pongan en vigor los contratos formales.

En la administración central de Noruega, en cambio, los sistemas de contratación tienen muy poca importancia para los servidores públicos (Christensen y Lægreid, 1998c). En 1996, sólo el 9\% de los servidores públicos informó que los sistemas de contratos tenían una gran importancia en su propia esfera de trabajo; no obstante, el servicio civil de Noruega ha 
adoptado una versión "suave" de la subcontratación a través de la aplicación del método de la "administración por objetivos y resultados", sistema que, antes bien que orientarse hacia los individuos, se basa más en las agencias.

Un tipo de subcontratación lo constituyen los contratos entre el gobierno como comprador de rendimiento y las agencias en cuanto proveedores y abastecedores. El argumento es que los contratos mejoran tanto la eficacia como el rendimiento de cuentas, porque combinan la competencia comercial con un sistema más rígido de control del rendimiento. Cuando se dividen la política y los negocios mediante la utilización de contratos, se hace más fácil que las empresas públicas compitan, se facilita la comparación de la eficacia entre los sectores público y privado y entre los organismos públicos y se puede atraer con mayor facilidad a expertos en el mercado. Todos estos son argumentos que se esgrimen a menudo cuando se hace el análisis de los efectos de las reformas contractuales en Nueva Zelanda (Boston et al., 1996; Nagel, 1997).

Ahora bien, el hecho de dividir organismos públicos que funcionan bien en unidades orgánicas que desempeñen los papeles de propietarias, proveedoras y compradoras podría provocar un debilitamiento de la experiencia pública, un incremento del uso de los recursos a través del empleo de más personal que antes, la contratación de asesores privados costosos y tendencias a la creación de monopolios o carteles privados. Un efecto del aumento de la utilización de los contratos es la disminución de las relaciones de cooperación; y otro es el incremento de los salarios y las fortunas de los funcionarios ejecutivos. Asimismo, se argumenta que parece haber pocos estudios bien documentados en los que se demuestre que el incremento de la competencia y la utilización de contratos mejoran los servicios y hacen que los precios bajen.

Otro tipo de subcontratación afecta funciones que tradicionalmente han sido mantenidas ajenas a la competencia, como el asesoramiento en cuestiones normativas (Boston et al., 1996: 6). En los tres países estudiados, siempre ha sido evidente que el asesoramiento a los líderes políticos en cuestiones normativas debería provenir de los servidores públicos permanentes de alta jerarquía, basado en la experiencia profesional; pero Australia y Nueva Zelanda han abierto ese tipo de asesoramiento a la subcontratación, lo que ha provocado la competencia entre las firmas de asesoramiento privadas, que emplean a antiguos servidores públicos, y los secretarios y otros líderes administrativos permanentes (Martin, 1998: 71-95). Lo anterior se añade a los procesos políticos siempre en marcha entre los líderes políticos, tanto en el gobierno como en los partidos y relacionados con los grupos de intereses, para decidir acerca del contenido de las diversas políticas.

Evidentemente, una de las razones para recurrir a los contratos es debilitar la burocracia y fortalecer el liderazgo político, algo que puede lograrse si los asesores privados logran convencer a los líderes políticos 
sobre todo de lo que a estos últimos les gustaría oír o de lo que preferirían hacer. Otra de las razones para recurrir a la subcontratación es aumentar la calidad del asesoramiento y la variedad de las premisas de decisión, en busca de alternativas bien documentadas al asesoramiento de los líderes administrativos.

Pero también es muy probable que esa forma de organización genere ambigüedad y debilite el liderazgo político. Los actores privados y los líderes administrativos podrían establecer redes y alianzas que actuaran en contra del liderazgo político, tendencia ya observada en Estados Unidos; por otra parte, los actores privados podrían dar asesoría que consistiera en soluciones mal disfrazadas para favorecer a los grupos de intereses y de presión, probablemente sin que ello incrementara la calidad de las premisas de decisión. Además, la confianza entre los líderes políticos y administrativos podría disminuir debido al desarrollo de la competencia entre los asesores en cuestiones normativas. Como podemos ver, la contratación de asesoramiento en cuestiones normativas tiene límites claros. No parece probable que aumente la eficiencia o la efectividad con las que dicho asesoramiento se produce y existe un gran riesgo de que surja un comportamiento oportunista entre los proveedores de asesoramiento y se genere un problema más grave con respecto a la coordinación de las políticas (Boston, 1994:1).

Un tercer tipo de subcontratación es la competencia por las auditorías en Australia y Nueva Zelanda, competencia que provoca una división estructural en la organización de las auditorías entre una unidad administrativa y una unidad que lleva a cabo la auditoría en la práctica en competencia con firmas privadas (Guthrie y Parker, 1998). Esta forma de organización puede plantear interrogantes acerca de la independencia y neutralidad del proceso de auditoría, lo cual es en particular el caso de un nuevo tipo de auditoría con una importancia creciente: la auditoría del rendimiento, que deja la puerta abierta al desarrollo de procesos políticos más típicos, a la construcción de alianzas y al empleo de un poder discrecional en el proceso de auditoría.

Un cuarto tipo de subcontratación, como elemento del modelo de la nueva administración pública, se refiere al reclutamiento y el empleo. En ese tipo de contratación, la creciente utilización de contratos individuales de corto tiempo reemplaza al empleo más permanente basado en los contratos colectivos. Lo anterior es el resultado de un mercado de mano de obra más competitivo, tanto dentro del servicio civil como entre los sectores público y privado, que a su vez ha provocado que las compensaciones se basen con menos frecuencia en la posición y la antigüedad, que los sistemas de paga se basen más en el mercado y en el rendimiento, que haya un menor interés en la pertenencia a los sindicatos y que se recurra más a menudo a los asesores y abogados privados para negociar los salarios. 
Este tipo de subcontratación es más visible en Nueva Zelanda, pero también es evidente en Australia. Por lo demás, el modelo de la nueva administración pública ha tenido parte en la transformación de la demografía del servicio civil o de algunas porciones de él. Los ejemplos de ello son los economistas que, a partir del Ministerio de Hacienda en ambos países, han proliferado y llegado a predominar en el servicio civil y abogan por más modelos de "racionalismo económico" (Campbell y Halligan, 1992: 105). Noruega introdujo incluso una versión "ligera" del sistema de contratación individual para los servidores públicos de alta jerarquía, con más devolución estructural de facultades, mayor flexibilidad y más elementos del sistema de paga basada en el mercado y en el rendimiento. En la práctica, no obstante, Noruega se ha mostrado renuente a hacer un empleo activo de ese nuevo sistema de paga, en especial cuando se trata de los contratos individuales y del elemento de paga basada en el rendimiento (Lægreid, 1994 y 1997). En ese país, el sistema acabó siendo un caso de prueba para el consenso sobre las reformas administrativas.

¿Qué efectos tienen los contratos individuales sobre el control político? Un punto de vista es que ese tipo de contratación está fortaleciendo el control político, porque los líderes políticos pueden politizar el reclutamiento de los líderes administrativos y hacerlos responsables más directamente, debilitando los principios tradicionales del mérito (Boston $e t$ al., 1991). Los ejecutivos principales nombrados mediante los contratos pueden ser más renuentes a dar asesoría "franca y sin temor a las consecuencias" a los políticos; además, la estructura de incentivos, cuya brecha entre los líderes administrativos y los servidores públicos de menor jerarquía se amplía cada vez más, está incrementando la lealtad política de los burócratas de mayor jerarquía. Campbell y Halligan (1992: 31) llegan a la conclusión de que uno de los efectos de las reformas relacionadas con el modelo de la nueva administración pública consiste en que los políticos y los burócratas de alta jerarquía de Australia viven más en simbiosis, debido a los salarios más altos ya la posición más alta de los líderes administrativos, en especial aquellos de las agencias centrales principales que cuentan con competencia económica.

Un argumento en contra de los contratos individuales es que dificultan la formulación de objetivos específicos y de indicadores de rendimiento para los servidores públicos de alta jerarquía. Otro argumento es que los contratos individuales incrementan la competencia y los conflictos entre las instituciones, los grupos y los individuos. Un tercer argumento es que el reclutamiento politizado podría dar como resultado el debilitamiento del liderazgo político, un aspecto esgrimido para explicar por qué Australia pudo embarcarse en el curso de la reforma que siguió. Se dice que la elite administrativa de economistas recién reclutada convenció a los líderes políticos sobre el nuevo rumbo de la reforma. 
En la práctica, además, no son los líderes políticos, sino los administrativos, los que formulan o controlan normalmente los contratos, como lo ejemplifica Nueva Zelanda. Los contratos individuales pueden también ser un reflejo de debilitamiento del control político a través del debilitamiento de la responsabilidad política, la identidad colectiva y el espíritu público de los líderes administrativos (Boston et al., 1996: 87). Mientras que el compromiso de los servidores públicos de alta jerarquía se había basado tradicionalmente en un sentimiento institucional y colectivo de largo plazo con un alto grado de lealtad política, ahora la situación se caracteriza más por los incentivos individuales estratégicos de corto plazo para los funcionarios ejecutivos que están a la búsqueda de las agencias que puedan ofrecerles el mejor contrato. Esa situación podría provocar el debilitamiento del control político, una menor continuidad en las instituciones públicas y que la experiencia profesional sea más pobre. El nuevo tipo de líderes administrativos es menos dependiente del liderazgo político en muchos sentidos.

Gregory (1998) hace notar que las reformas están llevando los procesos políticos en una dirección más tecnócrata en Nueva Zelanda. La cultura igualitaria tradicional está siendo reemplazada por una más elitista, fomentada por una nueva clase de burócratas de alta jerarquía, bien pagados con actitudes del sector privado, escépticos por lo general respecto a los procesos y el control políticos. El rendimiento de cuentas es más gerencial que político (Nagel, 1997). Al comparar la reorganización estatal en Australia, Dinamarca, Nueva Zelanda y Suecia, que incluye características típicas del modelo de la nueva administración pública, Schwartz (1994) llega a la conclusión de que los políticos han perdido influencia, mientras que los burócratas de alta jerarquía, entre ellos los "burócratas fiscales", son los vencedores. La lección general es que los nuevos regímenes de contratación adoptados para los servidores públicos de alta jerarquía no necesariamente concuerdan con las intenciones de los arquitectos de la reforma (Hood, 1998: 443).

El caso de la subcontratación de asesoramiento político en Nueva Zelanda y Australia ilustra los límites de los contratos en un sistema político-administrativo. La intención de la reforma es incrementar el control del gobierno sobre sus asesores, pero puede terminar disminuyéndolo. La incertidumbre política, como los cambios de ministros o gobiernos, incrementaría los problemas de la contratación externa y probablemente habría un mayor riesgo de comportamiento oportunista con consecuencias negativas para el mantenimiento de la confianza entre los ministros y los asesores (Boston, 1995: 98).

Una lección que nos deja el caso de Noruega es que la introducción de la técnica de "administración por objetivos" dificultó que los políticos cumplieran con sus obligaciones de definir objetivos claros, estables y 
coherentes y evaluar exhaustivamente los resultados. La técnica de

"administración por objetivos" ha tenido más éxito como método para el control administrativo de agencias subordinadas que como herramienta para mejorar la gobernanza y el control ( Christensen y Lægreid, 1998a). Esto puede reflejar el hecho de que los arreglos contractuales complican la función del servidor público como asesor en cuestiones normativas y de que incrementar el énfasis en el control gerencial reduce las posibilidades de gobernanza (Ingraham, 1996; Mascarenhas, 1990; Peters, 1996).

Una importante cuestión de principios respecto a la utilización de contratos es si éstos deben ser utilizados, en un sentido legal estricto, para cualquier clase de tarea del servicio civil fundamental o si su utilización debe ser diferenciada y llevarse a cabo principalmente en algunos sectores seleccionados. Los análisis sobre el asesoramiento político ponen de relieve este problema, pero también en Nueva Zelanda se da una fuerte discusión sobre si se debe utilizar la subcontratación en áreas como la salud, el trabajo social y la conservación y protección del medio ambiente. El argumento es que, cuando en ese país se han utilizado los contratos para discriminar inteligentemente entre los diferentes tipos de departamentos públicos principales con base en sus diferentes funciones y tareas, el resultado ha sido un fracaso (Gregory, 1995).

\section{La cuestión del rendimiento de cuentas y de la responsabilidad}

Un aspecto importante de la reforma administrativa es la cuestión del control político y del rendimiento de cuentas de los servidores públicos de alta jerarquía. El modelo de la nueva administración pública, en la que el rendimiento de cuentas se basa en el rendimiento personal, la competencia y las relaciones contractuales, representa una divergencia con respecto a la "antigua" administración pública, cuyas formas de rendimiento de cuentas se basan en los procesos, el control jerárquico y las tradiciones culturales. Se ha avanzado de los modelos de rendición de cuentas simples a los complejos (Day y Klein, 1987). La noción tradicional de rendimiento de cuentas — la autoridad vertical responsable ante el pueblo a través de los responsables electos de la formulación de las políticas es puesta en tela de juicio por el énfasis que se pone tanto en los clientes como en los resultados y cuya atención va de los administradores hacia abajo, hacia los ciudadanos, antes bien que hacia arriba, hacia los funcionarios electos.

En las reformas administrativas como el modelo de la nueva administración pública, se ha prestado mucha atención al rendimiento de cuentas de corte gerencial y se ha tomado muy poco en consideración la 
responsabilidad política. Por rendimiento de cuentas de corte gerencial queremos decir la obligación de rendir cuentas de la sección propia a aquellos en posiciones de autoridad de mayor jerarquía. La responsabilidad, por otra parte, se acepta por las acciones propias o de otros y es más subjetiva como sentimiento de obligación (Gregory, 1995: 60). Lo anterior significa que el rendimiento de cuentas podría ser un componente necesario, pero no suficiente, de la responsabilidad. El ser responsable entraña la capacidad para actuar, al igual que simplemente para rendir cuentas, y la preocupación por las consecuencias de ese actuar. El rendimiento de cuentas carece de elementos morales (Martin, 1997).

March y Olsen (1989) ponen de relieve la misma diferencia al establecer una distinción entre los procesos agregativos y los integradores en las organizaciones públicas. En los procesos integradores, los servidores públicos tienen un sentimiento de pertenencia, una historia y una tradición compartidas, que hace más fácil creer en la integración, en las obligaciones y en un propósito común y actuar en consecuencia (March, 1994). En los procesos agregativos, los actores están más dispersos y no sienten la integración; tienen que recibir incentivos para actuar en cierto sentido. En lugar de estar socializados en una cultura administrativa y un código de ética, están disciplinados para modificar su comportamiento mediante el empleo de diferentes clases de motivaciones (Lægreid y Olsen, 1984).

En Noruega y Nueva Zelanda ha existido tradicionalmente la doctrina de responsabilidad ministerial que establece que el ministro acepta tanto la culpa como el reconocimiento por las acciones de los administradores, los cuales deben permanecer anónimos e inmunes al reconocimiento o la culpa. Las reformas administrativas han aumentado el conocimiento del público sobre la identidad y las políticas de muchos servidores públicos de alta jerarquía y alejado más a los ministros del proceso administrativo y, por ende, desafían esa doctrina. En Nueva Zelanda, las reformas administrativas han alterado, quizá destruido, la doctrina de la responsabilidad ministerial; mientras tanto, se ha desarrollado una nueva versión del "rendimiento de cuentas" basada en las relaciones contractuales entre los ministros y sus principales ejecutivos (McLay, 1995: 197 y 205).

Esta cuestión presenta al menos dos facetas. En primer lugar, ¿cómo hacer para que los servidores públicos de alta jerarquía rindan cuentas por sí mismos?; y, en segundo lugar, ¿cómo proporcionar a los ministros mejores análisis y asesoramiento políticos que sirvan de sustento a sus actividades de formulación de políticas? Por un lado, el gobierno de Nueva Zelanda ha mejorado el rendimiento de cuentas de corte gerencial; por el otro, las reformas han provocado la fragmentación del sector público y que se reduzca la aceptación de la responsabilidad política por parte de los ministros. Lo anterior significa que sería necesario sopesar la reducción 
de la responsabilidad política contra las ganancias en efectividad y eficiencia (Boston et al., 1996: 360).

La preocupación por la eficiencia provoca que se tienda a exagerar la necesidad del rendimiento de cuentas gerencial, antes bien que a fomentar la responsabilidad política. La eficiencia no constituye garantía alguna del buen juicio político y social que es esencial para garantizar la responsabilidad y la legitimidad políticas genuinas (Gregory, 1998). La lucha por lograr el rendimiento de cuentas puede tener como precio la disminución del sentido de responsabilidad. El basar el rendimiento de cuentas en la especificación ex ante del rendimiento personal puede tener consecuencias imprevistas, como cuando las cuestiones que no han sido especificadas escapan al rendimiento de cuentas. Este problema no podrá remediarse mediante indicadores más detallados del rendimiento; antes bien, la solución podría venir de la adopción de un modelo de responsabilidad (Schick, 1996: 87).

Una de las grandes preocupaciones de las reformas administrativas se relaciona con la cuestión de equilibrar la libertad y el rendimiento de cuentas. El modelo burocrático tradicional, con poca libertad y poco rendimiento de cuentas sobre los resultados, pero con una gran responsabilidad por que se sigan las reglas, ha sido un modelo de administración pública extraordinariamente exitoso y durable. En la actualidad, los administradores públicos de todo el mundo buscan una mayor libertad, pero están más ansiosos por obtener un mejor rendimiento de cuentas. Un sistema que extiende la libertad a los gerentes, sin fortalecer su rendimiento de cuentas, debilita el poder de los políticos y es inferior al modelo de administración burocrática tradicional. Una reforma que entraña un desequilibrio entre la libertad y el rendimiento de cuentas es disfuncional. El sistema no funcionará bien si se da libertad a los funcionarios sin tener una expectativa clara sobre el rendimiento personal (Scott, 1996: 89).

Por otra parte, todas las grandes organizaciones tienen un dilema fundamental: se puede contar con un mejor rendimiento de cuentas (léase control) o con una mayor previsión (léase libertad), pero no se puede tener ambas cosas simultáneamente (Gregory, 1997: 96). El que los líderes administrativos pongan un énfasis más fuerte en la conducta emprendedora provocará probablemente que la coordinación y el control centrales sean más difíciles. Las ideas del modelo de la nueva administración pública acerca de la descentralización, la devolución estructural de facultades y la consecuente fragmentación crean la necesidad de una mayor coordinación con el propósito de asegurar la coherencia de las políticas en el gobierno (Peters y Savoi, 1995: 17; Hart, 1998: 286). Un argumento en favor de ello es que el dar más autoridad a los gerentes públicos para administrar programas muy probablemente dará como resultado el que se otorgue a los ministros una mayor capacidad para establecer criterios y prioridades 
centrales y una mayor intervención en las cuestiones de personal, con el propósito de resolver los problemas de pérdida del control sobre la aplicación de las políticas planteados por las reformas del modelo de la nueva administración pública (Maor, 1999). En conjunto, no obstante, dichas reformas parecen dar como resultado una pérdida del control político.

\section{La transformación del modelo de la nueva administración pública - en algunos países más que en otros}

La perspectiva transformadora esbozada apunta hacia varias dimensiones para explicar el fondo de la reforma pública, su contenido y sus efectos y consecuencias. Este último aspecto es el que se ha puesto particularmente de relieve en este artículo. En un sentido más técnico, la dimensión determinista-ambiental, ejemplificada por la crisis económica, es importante para explicar por qué los líderes de Nueva Zelanda comenzaron su ola reformista y, también, quizá parcialmente, por qué eligieron la senda de una reforma radical; pero, después de un tiempo, las reformas puestas en práctica en ese país parecieron adquirir características más ideológicas, con el predominio en el medio ambiente institucional de ideas económicas de desmantelamiento y reducción del Estado. Nueva Zelanda se convirtió en un caso de prueba del modelo de la nueva administración pública, apoyado por la Organización para la Cooperación y el Desarrollo Económicos, una historia de éxito que adquirió la calidad de mito. Y Nueva Zelanda pudo apoyarse en ese mito al desarrollar las reformas. Esa "simbiosis del mito" también parece haber sido importante para el desarrollo de las reformas en Australia, aun cuando el contenido de las reformas en ese país fue diferente en muchos aspectos al caso de Nueva Zelanda.

En comparación con los otros dos países, el medio ambiente relacionado con la reforma fue menos "amenazante" en Noruega (Christensen y Lægreid, 1998c). No se avecinaba ninguna crisis económica evidente que pudiera dar inicio a una ola reformista y, aun cuando se plantearon más interrogantes que nunca acerca de la eficiencia del servicio civil, el sector público contaba con un gran apoyo durante los años 70 y principios de los 80. Lo anterior dio como resultado que, cuando se emprendieron las reformas a finales de la década de los 80 , su inicio fuese tardío y lento y su contenido menos extremo.

Ahora bien, cuando se pasa a la dimensión más nacional e interna, tanto las variables estructurales como las culturales muestran un cuadro más complejo y desconcertante. En cuanto estados benefactores 
industrializados, existen importantes similitudes entre los tres países: en

la estructura de sus sistemas político-administrativos, en su cultura política y administrativa, en sus tradiciones corporativistas y en la fuerza e ideología de los partidos laboristas, características todas que llevarían a esperar que las reformas serían graduales; pero entre ellos existen también algunas diferencias que pueden explicar los diferentes rumbos de las reformas, como la importancia del modelo Westminster en Australia y Nueva Zelanda, las características federalistas de Australia y la homogeneidad estructural y cultural de Noruega. Lo que es particularmente desconcertante es que en Australia y Nueva Zelanda hayan sido los gobiernos laboristas los que iniciaron las reformas relacionadas con el modelo de la nueva administración pública (Castles et al., 1996), mientras que, en Noruega, de manera muy similar a como ocurrió en muchos otros países, el Partido Laborista se mostró mucho más renuente.

La crisis económica parece explicar por qué Nueva Zelanda decidió iniciar las reformas, pero las condiciones internas no explican fácilmente por qué eligió un rumbo extremo (Goldfinch, 1998). Por el contrario, se podía haber esperado que las reformas fuesen más graduales y con una menor influencia de los modelos económicos simplistas debido a la incompatibilidad con la cultura político-administrativa ya que ninguna de las reformas importantes fueron un mandato del público; pero, una vez adoptado el curso radical, en vista del sistema Westminster, de la tradición de centralización y de la debilidad de las fuerzas compensatorias, es comprensible que las reformas fuesen puestas en vigor con energía, sin prestar mucha atención a los sentimientos del público en general. La fuerza de impulso fundamental de la reforma fue un pequeño grupo de elites institucionales estratégicamente situadas y encabezadas por el Ministerio de Hacienda; no hubo una oposición efectiva dentro de la burocracia, el gabinete o los sectores; y las reformas fueron puestas en práctica por dos partidos gobernantes diferentes (Goldfinch, 1998; Nagel, 1998); sin embargo, resulta desconcertante que los economistas del Ministerio de Hacienda hayan logrado tanta influencia sobre los líderes políticos fuertes que eran importantes para impulsar el proceso (Pallott, 1998).

En una evaluación del experimento de Nueva Zelanda, el autor llega a la conclusión de que el rendimiento orgánico ha mejorado, pero también de que existen varios problemas (Schick, 1996 y 1998). Los principales ejecutivos atribuyen la mayor parte de la mejoría del rendimiento gubernamental a la discrecionalidad otorgada a los gerentes a través de la devolución estructural de facultades, antes bien que a través de contratos formales, además de que la puesta en práctica de éstos entraña altos costos de transacción. Otro efecto secundario es que, en ocasiones, los contratos benefician los intereses personales a expensas de los intereses colectivos del gobierno; y las reformas basadas en un punto de vista 
economicista estrecho del comportamiento humano en las organizaciones pueden cambiar la conducta de los funcionarios en ese sentido: se puede esperar que actúen como si fuesen poco dignos de fiar, interesados, oportunistas y moralmente peligrosos (Gregory, 1995: 71).

El contractualismo también podría debilitar los valores tradicionales del servicio público, la responsabilidad personal y el profesionalismo. Existen temores de que la calidad del asesoramiento y los servicios en cuestiones de políticas podrían deteriorarse y de que el grado de coordinación de las políticas se haya reducido (Scott et al., 1990; Verheijen, 1998). Además, podría provocar que los gerentes adopten un enfoque de lista de control del rendimiento de cuentas: "Si no está especificado, no es responsabilidad mía" (Schick, 1998: 126). Algunas investigaciones empíricas indican que en Nueva Zelanda podría estar surgiendo una mentalidad más legalista entre los servidores públicos con menor antigüedad debido a la introducción del contractualismo (Gregory, 1998a). Las reformas amenazan el capital social que constituye el servicio público y hacen más difícil sostenerlo en el tiempo como una comunidad de confianza (Gregory, 1999); sin embargo, aún queda por analizar de manera sistemática el grado en que el modelo de la nueva administración pública provocará verosímilmente la corrosión del capital ético del servicio público (Hood, 1991: 16).

En Australia, las reformas administrativas parecen tener su principal explicación en una diversidad de factores internos. Después de muchos años sin una influencia política importante, el Partido Laborista necesitaba llegar al poder nuevamente, y las reformas públicas eran uno de los instrumentos para lograrlo. Vieron la necesidad de volver a definir las funciones políticas y administrativas y ello influyó marcadamente en el rumbo adoptado para la reforma, esto es, se puso menos énfasis inicial en los aspectos económicos y comerciales de la reforma que en Nueva Zelanda. La heterogeneidad del sistema federal de Australia podía obstruir la reforma, dificultando el control de su puesta en práctica, pero también podía favorecerla, basándose en la introducción de elementos radicales de la reforma en los estados. Otros obstáculos potenciales a la reforma eran también las tradiciones corporativistas y la tensión entre las facciones del Partido Laborista; pero los funcionarios de mayor jerarquía adoptaron los principios fundamentales del racionalismo económico (Pusey, 1991). Además, un primer ministro fuerte, como "patrocinador de la reforma", creó el impulso inicial para ella al generar un sentimiento de liderazgo colectivo y conquistar para la causa a los líderes de los sindicatos, quienes renuentemente aceptaron la reforma como necesaria para lograr que el Partido Laborista volviera al gobierno (Campbell y Halligan, 1992). Para sorpresa de muchos que habían apoyado al Partido Laborista en las elecciones, el primer ministro eligió para la reforma un rumbo influido más profundamente por los economistas del Ministerio de Hacienda de lo que 
se creía posible, considerando las tradiciones del partido y el programa que lo llevó a ganar las elecciones.

El caso australiano se complica aún más debido al hecho de que las soluciones a las cuestiones de la "maquinaria de gobierno" fueron una imitación de las del Reino Unido, mientras que otros elementos de la reforma, como algunos de los elementos comerciales que vinieron más tarde, fueron imitados de algunos estados de Australia y Nueva Zelanda; y toda esa complejidad dificulta tener una visión clara de los efectos de la reforma (Campbell y Halligan, 1992: 35; Verheijen, 1998: 274).

Los casos de Australia y Nueva Zelanda demuestran que las reformas radicales no necesariamente producen mejores resultados. La ventaja de la opción australiana sobre la neozelandesa consiste en que es menos probable que la coordinación sea un problema en el sistema australiano que en el más fragmentado sistema neozelandés. La introducción gradual de las reformas, combinada con los intentos por obtener un consenso amplio sobre la introducción de las reformas, parece haber tenido un efecto positivo en Australia (Verheijen, 1998). Una lección del caso australiano es la paradoja de que el aumento del control político ha provocado la reducción del control sobre el sistema (Halligan, 1997). El objetivo clave de la reforma en lo concerniente al control político era romper el monopolio del servicio civil sobre el desarrollo y el asesoramiento políticos y redistribuir el poder en el seno del poder ejecutivo en favor del ejecutivo político. El resultado probablemente ha sido una pérdida de control de las políticas públicas debido a la pérdida de confianza en la competencia del Estado.

En el caso de Noruega, los factores que desencadenaron la reforma, ya fuesen internos o externos, fueron muy pocos. La inexistencia de una crisis económica y la gran confianza en un sector público activo y extenso explican que la presión externa fuese relativamente menor. Ello, combinado con la turbulencia parlamentaria, los gobiernos minoritarios, las reformas impulsadas internamente por la burocracia y la cultura administrativa tradicional, incompatible probablemente con muchos elementos del modelo de la nueva administración pública, podría explicar por qué Noruega inició tarde las reformas relacionadas con ese modelo y eligió un rumbo de incremento gradual en su aplicación. Durante la década de los 90, no obstante, tanto las reformas administrativas como las relacionadas con la devolución estructural de facultades han ido cobrando más impulso en ese país, sin que hasta ahora se haya tenido que recurrir sino en menor medida al elemento de privatización experimentado en Australia y Nueva Zelanda. Las razones de ese tipo de evolución parecen haber sido tanto internas como externas. Por una parte, fue importante el que el Partido Laborista haya pasado por un periodo de introspección, en lucha con su identidad tradicional, y salido de él con una postura más favorable a las reformas del modelo de la nueva administración pública, pues eso provocó también algunos 
cambios en las actitudes de los sindicatos asociados al partido; por la otra, la adaptación gradual de Noruega a Estados Unidos, a través del tratado EEA, la presión de la Organización para la Cooperación y el Desarrollo Económicos y la convicción profunda sobre el proceso de mundialización generaron también una mayor aceptación que antes de las ideas de la reforma relacionada con el modelo de la nueva administración pública.

Los estudios sobre la aplicación del modelo de la nueva administración pública en el servicio civil de Noruega ponen de relieve que las reacciones a él son de renuencia, agrupadas y variadas (Christensen y Lægreid, 1998b y 1998c). De renuencia, porque se considera que pocos elementos de la reforma son importantes y efectivos. De grupo, porque se considera que los elementos gerenciales son mucho más importantes que las reformas estructurales y orientadas hacia el mercado, aun cuando relativamente pocos opinan que se haya cumplido de manera significativa con las metas establecidas. Variadas, porque, por lo general, el modelo de la nueva administración pública cuenta más con la aceptación de los líderes administrativos que con la de los funcionarios ejecutivos y más con la de los empleados en general y el personal de desarrollo que con la de los ejecutivos que ejercen funciones judiciales tradicionales. En los últimos años se ha puesto más énfasis en la transferencia de las actividades comerciales y es evidente que ello ha provocado una mayor confusión respecto a las nuevas funciones políticas y administrativas y posiblemente ha debilitado el control político tradicional. El control político de esas actividades es formalmente fuerte, pero en la práctica se considera inadecuado, tendencia fomentada por el mito internacional relacionado con el modelo de la nueva administración pública (Statskonsult, 1998).

\section{Conclusión: ¿menos control político y menos buen gobierno?}

Hemos argumentado que, por lo general, las reformas relacionadas con el modelo de la nueva administración pública podrían debilitar el control político, con lo cual queremos decir que los líderes administrativos de los departamentos y agencias centrales, como los líderes de las empresas públicas comerciales, están ganando en influencia, aunque también, de manera más general, los actores privados comerciales y los consumidores. Las reformas han generado más escepticismo sobre las soluciones colectivas, la despolitización del sector público y más conflictos acerca de qué es público (Boston et al., 1996: 356-357).

Los efectos mencionados parecen ser el resultado de muchos procesos entretejidos. En primer lugar se encuentra el predominio "ideológico" mundial de las normas y valores económicos relacionados con el modelo de la nueva 
administración pública, que transforman sustancialmente la cultura políticoadministrativa en muchos países. En segundo lugar, ese predominio ha ido acompañado por fuertes argumentos en favor de una mayor especialización horizontal y vertical del aparato público. La combinación de esos dos tipos de especialización ha preparado el terreno para la devolución estructural de facultades de las unidades y actividades comerciales, lo que significa una mayor fragmentación y un menor control político en general y, más particularmente, sobre las actividades comerciales. En tercer lugar, el modelo de la nueva administración pública ha incrementado por lo general la competencia y la utilización de contratos, transformando con ello la relación entre, por una parte, los líderes políticos y, por la otra, las instituciones subordinadas y los actores individuales subordinados. Esa relación parece poner más atención a los aspectos individuales de corto plazo y estratégicos, con lo que posiblemente debilita el perfil tradicional del compromiso y el espíritu de las instituciones y la colectividad.

Existen, por supuesto, puntos de vista diferentes sobre los efectos y consecuencias del modelo de la nueva administración pública que ponen de relieve el mensaje de que las consecuencias de los nuevos sistemas y estructuras gubernamentales raramente son de un solo tipo. Uno de ellos toma como punto de partida el hecho de que el modelo de la nueva administración pública ha sido el reflejo de una crisis internacional del sector público que abarca problemas económicos, de inercia, estructurales, de disminución de la confianza y de la calidad de los servicios, lo cual ha llevado a que se ponga el énfasis en los valores y normas económicos y en la transferencia de las actividades comerciales, la competencia o los contratos. Según ese punto de vista, el modelo de la nueva administración pública ha ayudado a muchos países, como Nueva Zelanda, a recuperar su fortaleza económica ya ser más efectivos y eficientes en muchos aspectos (Evans et al., 1996; Scott, 1996); sin embargo, la relación entre las reformas y los parámetros económicos es muy discutible: algunos podrían argumentar que Nueva Zelanda está económicamente peor ahora que lo que podría haber estado sin las reformas, mientras que otros pondrían de relieve que sigue siendo económicamente débil y vulnerable a pesar de las reformas.

Otro tipo de opinión adopta como su punto de partida una especie de necesidad de aclarar y fortalecer el control político. Se dice que los procesos políticos se han vuelto muy complejos, que los líderes políticos están teniendo problemas de capacidad, que los líderes administrativos están ganando en influencia y que el gobierno interviene en demasiadas actividades. En esa situación, los líderes políticos deben desempeñar una función que sea un tanto más limitada e inequívoca, lo cual implica un sector público más reducido, una mayor transferencia de actividades comerciales, más competencia y una definición más clara de las funciones de los líderes políticos y administrativos a través de contratos y sistemas de incentivos. Se dice que ello da 
como resultado un control político más fuerte, aun cuando lo que los líderes políticos afirmen controlar ahora sea más limitado. El control también está cambiando cualitativamente, porque se da más importancia a las directrices y el desarrollo generales de políticas en el largo plazo y menos a la intervención política específica en el corto plazo.

Una lección de las reformas del modelo de la nueva administración pública es que un sistema exhaustivo y rígido de indicadores del rendimiento, en el que se hagan grandes esfuerzos por supervisar y evaluar este último, podría fortalecer el control administrativo superior; sin embargo, el que dicho sistema mejore también o no el control político y el buen gobierno es una interrogante sin respuesta. El modelo de la nueva administración pública ha reemplazado un sistema basado en la confianza mutua entre los servidores públicos de las diferentes jerarquías y entre los políticos y los administradores con un sistema que fomenta potencialmente la desconfianza. La idea principal del modelo de la nueva administración pública consiste en que, aunque sólo los incentivos externos sean los correctos, el buen gobierno está garantizado, sin importar la personalidad de los individuos. El modelo de la nueva administración pública ha sido caracterizado como el escenario del peor caso de un plan institucional que no incluye ningún supuesto sobre la solidaridad, la identidad colectiva compartida o las actitudes democráticas entre los servidores públicos (Olsen, 1997: 222-224). Por el contrario, la "vieja" administración pública argumenta que, sin funcionarios que tengan una mentalidad cívica y un dominio de sí mismos, el buen gobierno es imposible; es difícil edificar instituciones administrativas democráticas y funcionales en un servicio civil en el que los burócratas sólo se sienten motivados por incentivos externos y beneficios privados. Consecuentemente, existe la necesidad de ir más allá del supuesto del escenario del peor caso y manifestar un mayor interés en la manera como la reforma administrativa da forma a la mentalidad, la personalidad y la identidad de los individuos y las colectividades. 


\section{Apuntes}

* Autorizado por David Arellano Gault, Diretor de la Revista Gestión y Política Pública. Ponencia preparada para su presentación en el Tercer Simposio Internacional sobre Investigación en Administración Pública, Universidad de Aston, Birmingham, 25 al 26 de marzo de 1999.

1 El original en inglés dice political governance. Luego de abundantes discusiones respecto del término governance en inglés, el Servicio de Traducción de la Comisión Europea decidió que se traduciría al español por gobernanza. El Diccionario de la Lengua Española consigna el término como "acción y efecto de gobernar o gobernarse"; únicamente habría que definir una segunda acepción que reflejara el nuevo significado como método o sistema de gobierno. Una vez consolidada, la nueva acepción permitiría distinguir entre "gobierno", "gobernabilidad" y "gobernanza" [N. del E.].

2 El concepto de la "devolución estructural de facultades" es lo que en inglés se conoce como structural devolution. La definición del término devolution es: "transferencia de poder y autoridad del gobierno central a los gobiernos locales"; en el caso de este artículo, como se verá más adelante, se refiere a la transferencia de poder a los diferentes planos y agencias subordinados a la administración pública [N. del T.].

\section{Bibliografía}

Allison, G. (1983), "Public and Private Managers: Are They Fundamentall y Alike in All Unimportant Respect?", en J.L. Perry y K.L. Kraemer (coords.), Public Management. Public and Private Perspectives, Palo Alto, Mayfield Publishing.

Aucoin, P. (1990), “Administrative Reform in Public Management: Principles, Paradoxes and Pendulums", Governance, vol. 3, pp. 115-137.

Boston, J. (1994), "Purchasing Policy Advice: The Limits to Contracting Out", Governance, vol. 7, no 1, pp. 1-30.

Boston, J., Martin J., Palloty J., Walsh P., (coords.). (1996), Public Management: The New Zealand Model, Auckland, Oxford University Press. . (1991), Reshaping the State: New Zealand's Bureaucratic Revolution, Auckland, Oxford University Press.

Brunsson, N. (1989), The Organization of Hypocrisy. Talk, Decisions and Action in Organizations, Nueva York, Wiley.

Brunsson, N., Olsen J.P. (1993), The Reforming Organization, Londres y Nueva York, Rutledge.

Campbell, C., Halligan, J. (1992), Political Leadership in an Age of Constraint: The Experience of Australia, Pittsburgh, Pittsburgh UniversityPress. 
Castle, F.G. (1993), “Changing Course in Economic Policy: The English-Speaking Nations in the 1980s", en F.G. Castle (coord.), Family of Nations, Aldershot, Dartmouth.

Castles, F. (1989), "Big Government in Weak States: The Paradox of State Size in EnglishSpeaking Nations of Advanced Capitalism", Journal of Commonwealth and Comparative Studies, no 27, pp.267-293.

Castles, F., Gerritsen, R., Vowles J. (1996), The Great Experiment: Labor Parties and Public Policy Transformation in Australia and New Zealand, Auckland, Auckland University Press.

Cheung, A.B.L. (1997), "Understanding Public-Sector Reform: Global Trends and Diverse Agendas", International Review of Administrative Sciences, vol. 63, no 4, pp. 435-458.

Christensen, T. (1997), "Structure and Culture Reinforced — The Development and Current Features of the Norwegian Civil Services System", ponencia presentada en la Conferencia sobre el Sistema del Servicio Civil en una Perspectiva Comparativa, Universidad de Indiana, Bloomington, 5 al 8 de abril.

(1991), "Bureaucratic Roles, Political Loyalty and Professional Autonomy”, Scandinavian Political Studies, vol. 14, no 4, pp. 303-320.

Christensen, T., Egeberg, M. (1997), "Sentraladministrasjonen —en oversikt over trekk ved departementer og direktorater", en T. Christensen y M. Egeberg (coords.), Forvaltningskunnskap, Oslo, Tano Aschehoug.

Christensen, T., LÆgreid, P. (1998a), Den moderne forvaltning, Oslo, Tano Aschehoug. (1998b), "New Public Management —Design, Resistance or

Transformation?", ponencia presentada en la Reunión Anual de la American Political ScienceAssociation, Boston, 3 al 6 de septiembre. (1998c), "Administrative Reform Policy: The Case of Norway", International Review of Administrative Sciences, no 64, pp. 457-475. .(1998d), "Public Administration in a Democratic Context - A Review of Norwegian Research”, en N. Brunsson y J. P. Olsen (coords.), Organizing Organizations, Bergen, Fagbokforlaget.

Christensen, T., Peters, B.G. (1999), Structure, Culture and Governance: A Comparative Analysis of Norway and the United States, Maryland, Rowman \& Littlefield.

DAy, P., KLEIN, R. (1987), Accountability. Five Public Services, Londres, Tavistock Publishers.

EgEberG, M. (1989), “Om a organisere konkurrendere beslutningspnnsipper inn i myndighetsstrukturer”, en M. Egeberg(coord.), Institus-jonspolitikk og forvaltningsutvikling - bidrag til en anvendt statsvi-tenskap, Oslo, Tano Aschehoug.

Evans, L., et al. (1996), "Economic Reforms in New Zealand 1984-95. The Pursuit of Efficiency”, Journal of Economic Literature, no 34, diciembre, pp. 1856-1902.

GoldFinch, S. (1998), "Remarking New Zealand's Economic Policy: Institutional Elites as Radical Innovators 1984-1993”, Governance, vol. 11, no 2, pp. 177-208.

Gregory, R. (1999), "Social Capital Theory and Administrative Reform: Maintaining Ethical Probity in Public Service", Public Administration Review, vol. 59, no 1, pp. 63-75.

.(1998a), "The Changing Face of the State in New Zealand: Rolling Back the Public Service?", ponencia presentada en la Reunión Anual de la American Political Science Association, Boston, 3 al 6 de septiembre.

.(1998b), "Political Responsibility for Bureaucratic Incompetence:

Tragedy at Cave Creek”, Public Administration, no 76, otoño, pp. 519-538.

Gregory, R. (1997), "After the Reforms: Some Patterns of Attitudinal Change among Senior Public Servants in Canberra and Wellington", Australian Journal of Public Administration, vol. 56, no 1, pp. 82-99.

.(1995), "Accountability, Responsibility and Corruption: Managing the 'Public Production Process", en J. Boston (coord.), The State under Contract, Wellington, Bridget Williams Books. 
GrønLIE, T. (1998), "Drømmen om en konkurransetilpasset stat —Ytre fristilling som styringspolitisk redskap - 1994-1995”, en T. Grønlie y P. Selle (coords.), Ein stat? Fristillingas fire ansikt, Oslo, Samlaget.

Grønlie, T., Selle, P. (coords.). (1998), Ein stat? Fristillingas fire ansikt, Oslo, Samlaget. Guthrie, J., Parker, L.D. (1998), “'Managerialism' and 'Marketisation' in Financial Management Change in Australia”, en O. Olson, J. Guthrie y C. Humphrey (coords.), Global Warning! Debating International Developments in New Public Financial Management, Oslo, Cappelen Akademisk.

Halligan, J. (1998), “Comparing Public Service Reform in OECD Countries”, en J. Halligan (coord.), Public Service Reform, Centro para la Investigación sobre Administración en el Sector Público, Universidad de Australia en colaboración con la Asociación Internacional de Escuelas e Institutos de Administración.

. (1997), "Paradoxes in Reform: Australia", ponencia para el Proyecto sobre Paradojas en la Reforma del Sector Público, Berlín, 25 al 27 de septiembre.

. (1996), "Balancing Principles and Pragmatism", en J.P. Olsen y B.G.

Peters, Lessons from Experience: Experiential Learning in Administrative Reforms in Eight Democracies, Oslo, The Scandinavian University Press.

Hart, J. (1998), “Central Agencies and Departments: Empowerment and Coordination”, en B. Guy Peters y D.J. Savoie (coords.), Taking Stock: Assessing Public Sector Reforms, Montreal, McGill-Queen's University Press.

Hesse, J.J., Hood, C. Peters, B.G. (1999), "Paradoxes in Public Sector Reform: Soft Theory and Hard Cases”, en J.J. Hesse, C. Hood y B. G. Peters (coords.), Paradoxes in Public Sector Reform, Baden- Baden, Nomos, en preparación.

Hood, C. (1998), "Individualized Contracts for Top Public Servants: Copying Business, Path-Dependent Political Re-Engineering- or Trobriand Cricket?", Governance, vol. 11, no 4, pp. 443-462.

(1996), "Exploring Variations in Public Management Reform of the 1980s”, en H.A.G.M. Bekke, J.L. Perry y T.A.J. Toonen (coords.), Civil Service Systems, Bloomington, Indiana University Press. (1995), “The New Public Management in the 1980's. Variations on a Theme", Accounting, Organization and Society, vol. 20, no 2-3, pp. 93-109. .(1991), “A Public Management for All Seasons?”, Public Administration, no 69, primavera, pp. 3-19.

Ingraham, P.W. (1996), “The Reform Agenda for National Civil Service System: External Stress and Internal Strain”, en H. A. G. M. Bekke, J.L. Perry y T.A.J. Toonen (coords.), Civil Service Systems, Bloomington, Indiana University Press.

Keating, M., Holmes, M. (1990), “Australia's Budgetary and Financial Management Reform”, Governance, vol. 3, no 2, pp. 168-185.

Keauden, P., Van Mierlo, H. (1998), "Theories of Public Management Reform and Their Practical Implication”, en T. Verheijen y D. Coombes (coords.), Innovation in Public Management, Cheltenham, Edward Elgar.

Kettr, D.F., "The Global Revolution in Public Management: Driving Themes, Missing Links", Journal of Policy Analysis and Management, vol. 16, o 3, pp. 446-462.

LÆgreid, P. (1997), "Pay Reforms for Top Civil Servants in Norway: Towards Market and Performance Pay or Business as Usual?", Documento de Trabajo no 03, LOS Center, Bergen.

. (1994), "Going against the Cultural Grain: Norway", en C. Hood y B.G. Peters (coords.), Rewards at the Top, Londres, Sage.

LÆgreid, P., Olsen, J.P. (1984), “Top Civil Servants in Norway: Key Players on Different Teams", en E.N. Suleiman (coord.), Bureaucrats and Policy Making, Nueva York, Holmes \& Meier. 
Legreid, P., Roness, P.G. (1999), “Administrative Reform Programes and Institutional Response in Norwegian Central Government", en J.J. Hesse, C. Hood y B. G. Peters (coords.), Paradoxes in Public Sector Reform, Baden-Baden, Nomos, en preparación. . (1998), "Fra einskap til mangfald. Eit perspektiv pa indre fristilling i statem”, en T. Grønlie y P. Selle (coords.), Ein stat? Fristillingas fire ansikt, Oslo, Samlaget.

M arch, J.G. (1994), A Primer on Decision Making, Nueva York, The Free Press.

M arch, J.G.; Olsen, J.P. (1989), Rediscovering Institutions: The Organizational Basis of Politics, Nueva York, The Free Press.

Mascarenhas, R. C. ( 1996), Government and the Economy in Australia and New Zealand, San Francisco, Austin \& Winfield.

(1990), "Reform of Public Service in Australia and New Zealand", Governance, vol. 3, no 1, pp. 75-95.

Maor, M. (1999), “The Paradox of Managerialism”, Public Administration Review, vol. 59, no 1, pp. 5-18.

Martin, J. (1998), Reorienting a Nation: Consultants and Australian Public Policy, Aldershot, Ashgate.

. (1997), "Changing Accountability Relations: Politics, Customers and the Market", PUMA/PAC, vol. 97, no 1, París, OCDE.

Mcintosh, K., Shauness, J., Wettenhall, R. (1997), Contracting Out in Australia: An Indicative Story, University of Canberra, Center for Research in Public Sector Management.

McLeay, E. (1995), The Cabinet and Political Power, Auckland, Oxford University Press.

Melleuish, G. (1998), The Packaging of Australia: Politics and Culture Wars, Sydney, University of New South Wales Press.

Meyer, J. ., Rowan, B. (1977), "Institutionalized Organizations: Formal Structure as Myth and Ceremony", American Journal of Sociology, no 83, septiembre, pp. 340-363.

Mulgan, R. (1992), "The Elective Dictatorship in New Zealand", en H. Gold (coord.),New Zealand Politics in Perspective, Auckland, Longman.

Nagel, J.H. (1998), "Social Choice ina Pluralitarian Democracy: The Politics of Market Liberalization in New Zealand", British Journal of Political Science, no 28, pp. 223-267. (1997), "Editor's Introduction", Journal of Policy Analysis and Management, vol. 18, no 3, pp. 357-381.

OCDE. (1996b), Ministerial Symposium on the Future of Public Services, París, OCDE. (1996a), Globalization: What Challenges and Opportunities for Governments?, PUMA, París, OECD.

. (1995), Governance in Transition, París, OCDE.

Olsen, J.P. (1998), "Civil Service in Transition -Dilemmas and Lessons Leamed”,en-J.J. Hessey T.A. J. Toonen (coords.), The European Yearbook of Comparative Government and Public Administration, vol.3/1996, pp. 389-406, Baden-Baden, Nomos. (1997), "Institutional Designin Democratic Context", Journal of Political Philosophy, vol. 5, no 3, pp. 203-229.

. (1996), "Norway: Slow Learner — or Another Triumph of the

Tortoise?", en J.P. Olsen y B.G. Peters (coords.), Lessons from Experience, Oslo, The Scandinavian University Press.

. (1983), "The Dilemmas of Organizational Integration in Government", en J .P. Olsen, Organized Democracy. Political Institutions in a Welfare State - The Case of Norway, Oslo, The Scandinavian University Press.

Olsen, J.P., Peters, B.G. (coords.). (1996), Lessons from Experience, Oslo, The Scandinavian University Press. 
Olsen, J.P., Roness, P.G., Saetren, H. (1982), "Norway: Still Peaceful Coexistence and Revolution in Slow Motion", en J.J.Richardson (coord.), Policy Styles in Western Europe, Londres, Allen \& Unwin, pp.7-79.

Pallot, J. (1998), “The New Zealand Revolution”,en O. Olson, J. Guthrie y C. Humphrey (coords.), Global Warning! Debating International Developments in New Public Financial Management, Oslo, Cappelen Akademisk Forlag.

Peters, B. G. (1996), The Future of Governing: Four Emerging Models, Lawrence, The University of Kansas Press.

Peters, B. G., Savoie, D.J. ( coords. ) (1998), Taking Stock: Assessing Public SectorReforms, Montreal, The McGill-Queen's University Press.

(1995), Governance in a Changing Environment, Montreal, The McGill-Queen's University Press,

Pollitt, C. (1995), “Justification by Works or by Faith", Evaluation, vol. 1, no 2, pp. 133-154.

Pusey, M. (1991), Economic Rationalism in Canberra, Nueva York, The Cambridge University Press.

Power, M. (1994), The Audit Explosion, Londres, Demos.

Røvıк, K.A. (1998), Moderne organisasjoner: Trender i organisasjonstenkningen vedtusenarsskiftet, Bergen, Fagbokforlaget. . (1996), "Deinstitutionalization and the Logic of Fashion", en B. Czarniawska y G. Sevon (coords.), Translating Organizational Change, Nueva York, De Gruyter.

Sсніск, А. (1998), "Why Most Developing Countries Should Not Try New Zealand's Reforms", The World Bank Research Observer, vol. 13, no 1, pp. 121-131.

. (1996), The Spirit of Reform: Managing the New Zealand State Sector in a Time of Change, informe preparado para la Comisión de Servicios Estatales (State Services Commission) y el Ministerio de Hacienda, Wellington.

Schwartz, H. (1994), "Small States in Big Trouble: State Reorganization in Australia, Denmark, New Zealand and Sweden in the 1980's", World Politics, no 46, pp. 527-555.

Sсотт, G.C. (1996), Government Reform in New Zealand, Washington, D.C., International Monetary Fund.

Scott, G.C., Bushnell, P., Salle, N. (1990), "Reform on Core Public Sector: New Zealand Experiences”, Governance, vol. 3, no 2, pp.138-167.

StatsKonsult (1998), I godt selskap. Report 1998, Oslo, Statskonsult.

Stewart, J., Kimber, M. ( 1996), “The Transformation of Bureaucracy? Structural Change in the Commonwealth Public Service 1983-93", Australian Journal of Public Administration, vol. 55, no 3, septiembre, pp. 37-48.

Verhejen, T. (1998), "Public Management Reform in New Zealand and Australia", en T. Verheijen y D. Coombes (coords.), Innovation in Public Management, Edward Elgar, Cheltenham.

Wettenhall, R. (1998), "Privatization in Australia: How Much and What Impact?", ponencia presentada en el $45^{\text {th }}$ Executive Council Meeting and Seminar - Workshop on Administration in Transition, Eastern Regional Organization for Public Administration, Macao, 26 al 30 de octubre.

Yeatman, A. (1987), "The Concept of Public Management and the Australian State in the 1980's", Australian Journal of Public Administration, vol. 46, no 4, pp. 339-353. 


\section{A nova administração pública: o equilíbrio entre a governança política e a autonomia administrativa \\ Tom Christensen e Per Lagreid}

As reformas modernas, como o modelo denominado "Nova Administração Pública", representam uma tendência à globalização: estão se difundindo com rapidez em todo o mundo e exercendo uma influência importante e similar nas atividades das organizações públicas. Este artigo questiona este ponto de vista, mediante a análise dos diferentes efeitos e consequiências que teve o modelo da nova administração pública quando se colocaram em prática os sistemas de serviço civil da Austrália, Nova Zelândia e Noruega. Da perspectiva de transformação, interpretamos estes efeitos como o resultado de uma combinação de idéias globais, características culturais nacionais e controle político e administrativo das reformas. Em particular, centramos nossa atenção na maneira como o modelo da nova administração pública afeta a relação entre as lideranças políticas e administrativas e nos perguntamos se os políticos estão perdendo o controle devido ao predomínio das normas e valores econômicos, à devolução estrutural de capacidades ou à contratação e transformações do espírito público dos servidores civis.

\section{La nueva administración pública: el equilibrio entre la gobernanza política y la autonomía administrativa \\ Tom Christensen y Per Lagreid}

Se dice que las reformas modernas, como el modelo denominado "Nueva Administración Pública", representan una tendencia a la globalización: se están difundiendo con rapidez en todo el mundo y están ejerciendo un efecto importante y similar en las actividades de las organizaciones públicas. En este artículo se pone en tela de juicio ese punto de vista mediante el análisis de los distintos efectos y consecuencias que tuvo el modelo de la nueva administración pública cuando se puso en práctica en los sistemas del servicio civil de Australia, Nueva Zelanda y Noruega. Desde la perspectiva de la transformación, interpretamos esos efectos como el resultado de una combinación de ideas globales, características culturales nacionales e intentos de control político y administrativo de las reformas. En particular, centramos nuestra atención en la manera como el modelo de la nueva administración pública afecta la relación entre los liderazgos políticos y administrativos y nos preguntamos si los políticos están perdiendo el control debido al predominio de las normas y valores económicos, a la devolución estructural de facultades o a la contratación y a las transformaciones del espíritu público de los servidores civiles.

\section{New Public Management - the trade-off between political governance and administrative autonomy \\ Tom Christensen and Per Lagreid}

Modern reforms, such as New Public Management, are said to represent a globalization trend; they are traveling fast around the world having major and similar impact on the activities of public organizations. This paper questions this view by analyzing the differentiated effects and implications of NPM when implemented in the civil service systems in Australia, New Zealand and Norway. From the transformation perspective

Abr-Jun 2001

Tom

Christensen es investigador del Departamento de Ciencia Política en la Universidad de Oslo.

Per Lægreid es investigador del Departamento e Administración y Teoría de la Organización en el LOS-Center de la Universidad de Bergen. 
we interpret these effects as a result of a melding of global ideas, national cultural

features and attempts of political and administrative control of the reforms. We focus especially on how the relationship between political and administrative leadership is affected by NPM, asking whether the politicians are losing control, due to dominance of economic norms and values, to structural devolution, or to contracts and changes in the public ethos of civil servants. 